\title{
EDUCACIÓN, ECOTURISMO Y CONSERVACIÓN BIOCULTURAL EN LOS BOSQUES EN MINIATURA DEL CABO DE HORNOS
}

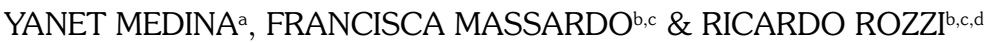

\section{RESUMEN}

El Parque Etnobotánico Omora desarrolla investigación, educación y conservación biocultural a largo plazo en Puerto Williams, Reserva de la Biosfera Cabo de Hornos, Chile. El 2008 se descubrió que esta reserva es un centro mundial de diversidad de flora no-vascular, sin embargo, la comunidad desconocía esta riqueza florística. Se investigaron las causas de este desconocimiento. Primeramente, se cuantificaron sesgos taxonómicos que favorecen (i) la flora vascular sobre la flora no-vascular y (ii) la flora exótica sobre la nativa en (a) los textos escolares y (b) los "imaginarios florísticos" de escolares de Puerto Williams. En segundo lugar, para corregir estos sesgos se utilizó la metodología de la Filosofía Ambiental de Campo (FILAC) para diseñar e implementar actividades educativo-recreativas que incorporaron y valoraron la flora no-vascular y la flora nativa en la educación formal y no-formal (incluido el ecoturismo). En tercer, se evaluó el impacto de la FILAC, con sus nuevas actividades y conceptos, para revertir el sesgo negativo hacia la flora no-vascular en la educación de los escolares y en la cultura cotidiana.

Los textos escolares también tuvieron marcados sesgos taxonómicos hacia la flora vascular y biogeográficos hacia la flora exótica. En el 2000 en los imaginarios de los escolares todas las plantas fueron vasculares y un $73,3 \%$ de ellas fueron exóticas. En contraste, en sus imaginarios el 2009, después de usar la FILAC, las proporciones de vasculares y no-vasculares fueron similares y un $44,4 \%$ de las especies fueron nativas. Por lo tanto, para revertir sesgos taxonómicos y biogeográficos en la educación, la metodología FILAC fue efectiva. Particularmente lo fueron la composición de metáforas y actividades de campo con preescolares, escolares, universitarios, ciudadanos de la comunidad local, guías de turismo, personal de la Armada de Chile y turistas.

Se demostró que utilizando la FILAC pueden visibilizarse especies poco conspicuas y reconocerse sus valores ecológicos, éticos, estéticos y económicos. La metodología FILAC propicia transformaciones bioculturales que generan cambios en la percepción y valoración de seres generalmente marginados de la cultura y la educación. La FILAC podría adaptarse para apreciar y conservar miríadas de diminutos seres vivos con que co-habitamos en otras regiones de Chile y del planeta.

a Programa de Magíster en Ciencias, Manejo y Conservación de Recursos Naturales en Ambientes Subantárticos, Universidad de Magallanes, Punta Arenas, Chile. \yanet.a.medina.m@gmail.com

b Centro Universitario Puerto Williams, Universidad de Magallanes. francisca.massardo@gmail.com

Instituto de Ecología y Biodiversidad, Chile.

d Department of Philosophy and Religion, University of North Texas, EE.UU. ricardo.Rozzi@unt.edu 
PALABRAS CLAVE: ecoturismo con lupa, ética biocultural, filosofía ambiental de campo, homogeneización biocultural, sesgo taxonómico.

\title{
EDUCATION, ECOTOURISM, AND BIOCULTURAL CONSERVATION IN THE MINIATURE FORESTS OF CAPE HORN
}

\begin{abstract}
The Omora Ethnobotanical Park develops long-term biocultural education, research, and conservation in Puerto Williams, Cape Horn Biosphere Reserve, Chile. In 2008 it was discovered that this reserve is a hotspot of diversity of non-vascular flora, however, the community was unaware of this floristic richness. The causes of this ignorance were investigated. First, we quantified the taxonomic biases that favor (i) vascular over non-vascular flora and (ii) exotic over native flora in (a) school texts and (b) the "floristic mindsets" of schoolchildren in Puerto Williams. Second, to correct these biases the Field Environmental Philosophy (FEP) methodology was used to design and implement educational-recreational activities that incorporated and valued non-vascular flora and native flora in formal and non-formal education (including ecotourism). Third, we evaluated the impact that FEP activities and concepts had to reverse the negative bias towards non-vascular flora in schoolchildren education and in everyday culture.

School texts had marked taxonomic biases favoring vascular flora and biogeographic biases favoring exotic flora. In 2000 , in the mindsets of schoolchildren all plants were vascular and $73.3 \%$ of them were exotic. In contrast, in their mindsets in 2009, after using FEP's methodology, the proportions of vascular and non-vascular were similar and $44.4 \%$ species were native. Therefore, to reverse both floristic biases, the FEP methodology was effective. Particularly effective were the composition of metaphors and field activities with preschoolers, schoolchildren, university students, citizens of the local community, tourist guides, Chilean Navy personnel, and tourists.

It was demonstrated that using FEP's methodology, inconspicuous species can be made visible and their ecological, ethical, aesthetic and economic values can be recognized by citizens. FEP fosters biocultural transformations that generate changes in the perception and appreciation about living beings that are generally marginalized from culture and education. FEP could be adapted to appreciate and conserve myriads of tiny living beings with which we co-inhabit other regions of Chile and the planet.
\end{abstract}

KEY WORDS: ecotourism with a hand-lens, biocultural ethics, field environmental philosophy, biocultural homogenization, taxonomic bias.

\section{INTRODUCCIÓN}

Las causas últimas de la actual crisis socioambiental residen en los hábitos de vida y valores que prevalecen en la sociedad global industrial y orientan sus relaciones con el mundo natural (Rozzi, 2001). Para resolver y afrontar esta crisis son necesarios cambios éticos (White, 2007) y una reapreciación de la diversidad biológica y cultural (Rozzi, 2001). Con este fin es esencial incorporar prácticas en la educación formal y no-formal que permitan reconocer y valorar la diversidad biocultural de cada región (Ojeda et al. 2018). Sin embargo, para incorporar la diversidad biocultural en la educación formal es necesario resolver dos limitaciones:

1) La falta de inclusión en los currículos de la mayoría de los seres vivos: sus ciclos de vida $e$ interacciones en los ecosistemas regionales.

2) Las escasas instancias de experiencias de co-habitación que tienen los estudiantes con la diversidad cultural y biológica regional.

Estas dos limitaciones conducen a los estudiantes y ciudadanos de la sociedad global a 
una crisis cognitiva, afectiva y vivencial, que los disocian de sus hábitats regionales (Rozzi et al. 2014). Los modelos pedagógicos actuales se basan mayoritariamente en clases expositivas que favorecen una actitud pasiva y desmotivan el pensamiento innovador y crítico; tienden a estar centradas en un profesor activo, cuyos estudiantes no son partícipes en su aprendizaje (Freire, 1973, 1993; Harlen, 2002; Vergara, 2006; González et al. 2009).

En el Programa de Conservación Biocultural Subantártica del Parque Etnobotánico Omora en Puerto Williams, capital de la provincia Antártica Chilena, hemos planteado que esta tendencia de modelos educativos expositivos debe revertirse y orientar, en cambio, una educación que reconecte a los estudiantes con sus hábitats regionales y que fomente una conciencia y experiencia de cohabitación con diversos seres humanos y especies biológicas con quienes compartimos los hábitats regionales (Rozzi et al. 2014). En un mundo complejo e interconectado confrontamos una crisis socio-ambiental global cada vez más desafiante y los académicos debemos asumir la responsabilidad de educar a los estudiantes para que puedan enfrentar el difícil momento histórico que están viviendo a través de una educación que fomente su creatividad (Nuño-Mayer, 2017). Para lograr este objetivo, necesitamos generar programas educativos que, además de conocimiento, brinden compromiso con el entorno y conciencia a través de experiencias concretas, promoviendo así el desarrollo sostenible como vía para el mejoramiento de la calidad de vida futura (Comité Técnico Asesor del Diálogo Nacional sobre la Modernización de la Educación Chilena, 1994; Rozzi et al. 1997, Leff, 2012).

Para promover una educación que favorezca la conservación biocultural, esto es, el bienestar de las diversas culturas y seres vivos, junto con las materias establecidas en los currículos, es fundamental considerar el conocimiento ecológico tradicional de las comunidades locales (Berghoefer et al. 2008, Carrero de Blanco \& García Tovar, 2008). Además, deben crearse espacios donde estudiantes y ciudadanos puedan experimentar procesos de reflexión para valorar y relacionarse crítica y responsablemente con su entorno (Feinsinger, 1987; Feinsinger et al. 1997; Hargrove, 2008). Una de las funciones más importantes que la educación debería cumplir en la actualidad es establecer puentes que faciliten el intercambio de experiencias y saberes; esto requiere reformar los actuales sistemas de educación formal (Arango et al. 2009).

La dificultad para superar las barreras físicas y conceptuales que disocian al sistema educativo de sus entornos bioculturales ha aumentado debido a que desde el año 2008 más del 50\% de la población del planeta se concentra en ciudades (Rozzi, 2013). En Chile, el 86,6\% de la población vive en zonas urbanas, y en la Región de Magallanes y Antártica Chilena alcanza más del $91,9 \%$ y llega al 90,2\% en la comuna más austral de nuestro país y del mundo: Cabo de Hornos (INE, 2017). La concentración en las urbes implica que la experiencia del contacto directo con la biodiversidad y los hábitats nativos regionales es cada vez más escasa (Vierikko et al. 2016). Las personas perciben la naturaleza de formas mediadas, controladas y sesgadas a través de filtros culturales universalizados y uno de ellos es la educación formal. Por ejemplo, en los textos escolares utilizados en la educación pública chilena entre 1975 y 1995 , menos del $20 \%$ de la fauna y flora descrita o ilustrada era nativa (Rozzi et al. 2008a).

La remota Región de Magallanes y Antártica Chilena no escapa a la tendencia de uniformización y homogeneización biocultural (sensu Rozzi, 2013). Por ejemplo, más de un $50 \%$ de su territorio continental está protegido por parques nacionales o reservas naturales; sin embargo, dentro de las ciudades la flora arbórea en las plazas de armas está dominada por especies de origen europeo o norteamericano (Rozzi et al. 2008a). Además, en la comuna de Cabo de Hornos $\left(55^{\circ} \mathrm{S}\right)$ los profesores del sistema público de educación poseen mayor conocimiento sobre especies de flora exótica (por ejemplo, rosas y manzanos, que no crecen en los archipiélagos australes) que sobre flora nativa local, que incluye especies icónicas como el árbol leñadura (Maytenus magellanica (Lam.) Hook. F.) o la flora más diversa de Chile en musgos (Rozzi et al. 2008a). La omisión de elementos nativos en textos y programas educativos, junto con la concentración de la población en las urbes, limitaría la relación cognitiva y afectiva de los escolares con su biodiversidad local. En la educación formal se padece una "ceguera" hacia la biodiversidad local que deriva en parte de una extinción de una 
experiencia cotidiana de los estudiantes en sus hábitats regionales (Poole et al. 2013, Rozzi et al. 2014, Celis-Diez et al. 2016).

\section{Sesgos taxonómicos}

En la Región de Magallanes y Antártica Chilena se ha descubierto recientemente que la flora más diversa y endémica es la flora novascular (Rozzi et al. 2008b). Esta pequeña flora carece de xilema y floema o cualquier tipo de tejido especializado en la conducción de agua y nutrientes, $e$ incluye musgos, hepáticas y antocerotes, que en conjunto se denominan briófitas (Goffinet \& Shaw, 2009). Esta flora distingue a Magallanes como una región singular desde el punto de vista florístico, puesto que en otras regiones del país y del mundo la riqueza de especies de plantas no-vasculares es 20 veces menor que aquella de plantas vasculares. Por ejemplo, en países megadiversos de Sudamérica, tales como Brasil, Colombia y Ecuador, la proporción de especies de plantas no-vasculares/ vasculares es inferior a 0,05 (Rozzi et al. 2008b).

Para conocer y valorar las características únicas de la flora de Magallanes, es necesario realizar una adaptación de los contenidos de la enseñanza de la botánica en la educación formal que permita incorporar la flora más idiosincrática de la región. También es necesario hacer esfuerzos transversales entre contenidos curriculares. Al incorporar la diversidad local de briófitas se sitúa el conocimiento en la región y se posibilita la intersección de la botánica con otras áreas, tales como la historia o la etnobiología, y ello porque un currículo transversal permite una educación integradora. Sin embargo, estudios preliminares señalan que la flora no-vascular queda casi completamente excluida de la educación formal en el plano de la región y del país (Rozzi, 2013). En Magallanes identificamos, entonces, que además de la "ceguera" hacia la flora nativa en general, existiría otra "ceguera" más sutil en la cultura y en la educación formal: un sesgo taxonómico en favor de la flora vascular (grandes árboles, arbustos y hierbas) que excluye a la flora no-vascular o briófitas.

El sesgo taxonómico que omite la mayor riqueza de la flora regional no sólo afecta a la educación formal, sino también a la educación no- formal (Lewis et al. 2018). Ello limita la percepción, el conocimiento y el disfrute de la flora más representativa de la región. El desconocimiento de este grupo de organismos, que imprime una identidad florística regional, restringiría también su valoración desde el punto de vista espiritual, estético y económico.

Este sesgo taxonómico tan evidente en Magallanes podría revertirse mediante cambios curriculares en la educación formal. Además, la educación ambiental debería ayudar al estudiante a conocer su entorno mediante prácticas activas de observación, experimentación $e$ indagación sobre el patrimonio natural y cultural de cada región (Tonucci, 2006). Estas prácticas fomentan posturas críticas y participativas respecto a la valoración, administración responsable y conservación del patrimonio biocultural (Novo, 2006; Rozzi, 2013). El filósofo ambiental estadounidense Eugene Hargrove plantea que la docencia debe adecuarse a cada cultura y región, y la enseñanza debe procurar valorar el medioambiente per se. Además, señala que para ello debe superarse la omnipresencia del valor económico asociado a una visión utilitarista. Esta superación es especialmente relevante hoy, cuando el valor no-económico de las cosas es considerado como una mera expresión de emociones personales (Hargrove, 2008), y de esta forma subestimado. De acuerdo a Hargrove (1997), la educación ambiental no debiera imponer nuevos valores, sino fortalecer y recuperar valores contenidos en las tradiciones culturales de las comunidades regionales o locales que se pueden expresar en forma positiva a través de la creación de espacios para la reflexión y el diálogo desde múltiples visiones.

La antropóloga y etnógrafa chilena Victoria Castro (2007) interpela a los investigadores y ciudadanos a asumir la responsabilidad de informar, emocionar y estimular la exploración y valoración del patrimonio biocultural de cada región. Este giro biocultural motiva cambios valóricos referidos a la relación ser humano-naturaleza en la acción cotidiana y mediante la educación formal y no-formal. Con el fin de contribuir a esta responsabilidad educativa, el Programa de Conservación Biocultural Subantártica ${ }^{1}$ ha desarrollado materiales y actividades de educación

Este programa es coordinado en Chile por la Universidad de Magallanes, el Instituto de Ecología y Biodiversidad y la Fundación Omora y en EE.UU. por la Universidad de North Texas. 
formal y no-formal en el Parque Omora con escolares, turistas y público general. Uno de los propósitos de este Programa ha sido revertir la omisión de la flora no-vascular en la educación. Para ello, desde el año 2000 ha desarrollado tres actividades programáticas de largo plazo. Primero, en marzo del 2000 incorporó un taller permanente de historia natural en el currículo del único establecimiento educativo de Puerto Williams (el Liceo Donald McIntyre Griffiths), con énfasis en los grupos de organismos que culturalmente son poco percibidos y valorados (plantas no-vasculares, invertebrados dulceacuícolas y marinos, algas submareales) (Contador et al. 2018; Lewis et al. 2018; Ojeda et al. 2018). Segundo, el 2001 implementó el Parque Omora, en la isla Navarino, con senderos interpretativos para la observación de la flora no-vascular, metafóricamente denominada "Bosques en Miniatura del Cabo de Hornos" (Rozzi et al. 2006). Tercero, el 2002 creó una innovadora actividad de turismo científico, el Ecoturismo con Lupa (Rozzi et al. 2006).

El objetivo general planteado en este artículo es evaluar las metodologías que han sido utilizadas en el Parque Omora para crear conciencia, compromiso y participación responsable del estudiante con su entorno en la educación formal, integrando la investigación ecológica y la ética ambiental. Además, proponemos nuevas metodologías. Para abordar este objetivo general, nos planteamos tres objetivos específicos:

(1) Cuantificar el sesgo taxonómico en favor de la flora vascular y en desmedro de la flora no-vascular en los textos utilizados en la educación formal pública en Chile.

(2) Proponer una actividad educativa y recreativa utilizando la metodología de la Filosofía Ambiental de Campo (FILAC, sensu Rozzi et al. 2010a) que contribuya a incorporar y valorar la flora no-vascular en la educación formal y no-formal, incluido el ecoturismo.

(3) Evaluar el impacto de conceptos asociados a la flora no-vascular en una actividad de turismo in situ en los medios de prensa y la cultura cotidiana de la ciudadanía de Magallanes. El propósito último de este trabajo es contribuir, desde el sur del mundo, a reformas en los programas educativos que acerquen a la educación con el conocimiento, valoración y conservación de la diversidad biocultural de cada región en nuestro país y el planeta. Este último fin es catalizado por la adscripción que el Parque Omora tiene con la red internacional de sitios de estudios socio-ecológicos a largo plazo (véase Rozzi et al. 2010a).

\section{Área de estudio}

Este trabajo se realizó en la Región de Magallanes y Antártica Chilena, con énfasis en la comuna de Cabo de Hornos. Las actividades prácticas de educación se desarrollaron principalmente en el Parque Omora, ubicado en la isla Navarino, 3 kilómetros al oeste de Puerto Williams, capital de la provincia Antártica Chilena (Fig. 1). Esta ciudad se ubica en la costa sur del canal Beagle, en la costa norte de la isla Navarino. Tiene 2.063 habitantes (INE, 2017) y cuenta con tres establecimientos educativos: el Jardín Infantil Multiétnico Familiar Ukika, dependiente de la Junta Nacional de Jardines Infantiles (JUNJI); el Jardín Infantil Pequeños Colonos, dependiente del Departamento de Bienestar de la Armada de Chile, y el Liceo Donald McIntyre con una matrícula cercana a 400 alumnos que depende de la I. Municipalidad de Cabo de Hornos.

El Parque Omora es un espacio públicoprivado de 1.070 ha concesionado a la Universidad de Magallanes y a la Fundación Omora por el Ministerio de Bienes Nacionales. Sus objetivos son desarrollar investigación, educación y conservación biocultural, y constituye el centro científico de la Reserva de la Biosfera Cabo de Hornos (en adelante $\mathrm{RBCH}$ ). En sus proyectos participan investigadores, profesionales y técnicos asociados al Programa de Conservación Biocultural Subantártica, quienes han definido al Parque Omora como un laboratorio natural para la educación formal y no-formal (Rozzi et al. 2010). En este parque los estudiantes del liceo de Puerto Williams y de otros establecimientos educacionales de la región encuentran un lugar ideal para explorar la flora no-vascular de la $\mathrm{RBCH}$, puesto que presenta los principales tipos de hábitats de la isla Navarino: i) complejo de tundra de Magallanes, ii) hábitat altoandino, iii) cuerpos y 


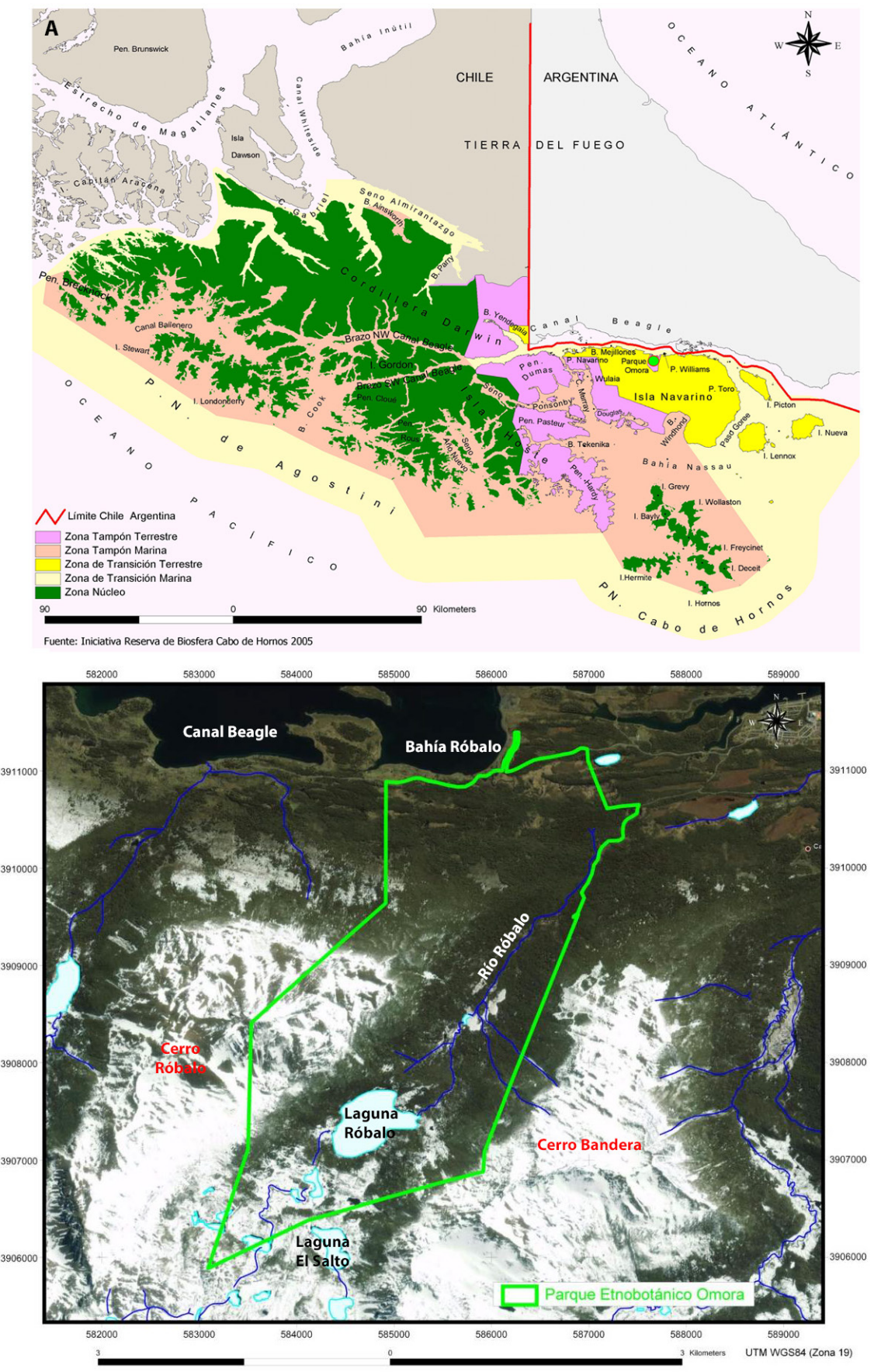

Fig. 1. A. El Parque Etnobotánico Omora (círculo celeste) se ubica en la Reserva de la Biosfera Cabo de Hornos (RBCH) creada el año 2005. La zonificación terrestre de la RBCH muestra las zonas núcleo con los parques nacionales de Agostini y Cabo de Hornos, las zonas tampón que incluyen mayoritariamente tierras fiscales y la franja costera, y las zonas de transición donde se encuentra Puerto Williams. En las áreas marinas, las zonas tampón incluyen aguas interiores y las zonas de transición rodean el tampón marino. El Parque Omora se ubica en la zona tampón terrestre y corresponde a un Sitio Prioritario para la Conservación de la Biodiversidad (CONAMA 2002) y es sitio co-fundador de la Red Chilena de Estudios Socio-Ecologicos a Largo Plazo (LTSER Chile), adscrita a la red internacional ILTER (International Long-Term Ecological Research Network). B. Límites del Parque Omora (1.070 ha) que protege gran parte de la cuenca del río Róbalo que abastece de agua bebestible a Puerto Williams. 
cursos de agua dulce, iv) bosques subantárticos de Magallanes (Rozzi et al. 2012a).

\section{METODOLOGÍA}

\section{Cuantificación del sesgo taxonómico}

El sesgo taxonómico hacia las plantas vasculares en la educación formal se evaluó cuantitativamente mediante un análisis de las ilustraciones incluidas en los textos de ciencias naturales utilizados en cada uno de los 12 niveles (ocho de enseñanza básica y cuatro de enseñanza media) en la educación pública en Chile el año 2009. Estos textos son entregados por el Ministerio de Educación a las Corporaciones Municipales y distribuidos a los establecimientos educacionales dependientes y particulares subvencionados. Se evaluaron los textos de Ciencias Naturales desde Primero hasta Octavo Año de Enseñanza Básica (8 textos), y los textos de Biología de Primero a Cuarto Año de Enseñanza Media (4 textos).

Para el análisis de la representación de la flora (vascular y no-vascular), en cada texto se registraron todas las ilustraciones que representaban uno o más elementos de vegetación -fotografías, dibujos y/o caricaturas- acompañados o no de otros elementos, como animales o hábitat. En cada imagen se consideró la presencia o ausencia de tipos de plantas, distinguiendo componentes en las siguientes categorías:

i) especies arbóreas reconocibles,

ii) esquema de árbol genérico (sin identificar especie),

iii) especies de plantas con flores reconocibles,

iv) esquemas de planta con flores (genérico) contando por separado cada color de flor,

v) especies de planta vascular sin flor reconocible,

vi) esquemas de planta vascular sin flor (genérico),

vii) especies de planta no-vascular

2 Este trabajo formó parte de la tesis de Magíster en Ciencias de Yanet Medina: Medina, Y. (2013). Bosques en miniatura del Cabo de Hornos: el turismo con lupa como herramienta para la educación, conservación y turismo científico en la reconocible $y$

viii) esquemas de planta no-vascular (genérico).

Para la evaluación del sesgo taxonómico se consideró como plantas vasculares a la sumatoria de las categorías "i-vi", y como plantas novasculares a la sumatoria de las categorías "vii-viii". Se definieron los índices de frecuencia según:

$$
\begin{gathered}
\text { \% flora vascular }=100 \times \sum \text { “i-vi" / } \\
\sum \text { ("i-vi" + "vii-viii") }
\end{gathered}
$$

\% flora no-vascular=100 x $\sum$ “vii-viii" /

$$
\sum \text { (“i-vi" + "vii-viii") }
$$

Para evaluar el sesgo hacia una planta exótica o nativa, cada registro de árbol, planta con flor, planta vascular sin flor y planta no-vascular reconocida a nivel de especie, se clasificó como especie nativa o exótica. A partir de estos registros, se calculó la frecuencia de especies exóticas y nativas según:

$$
\begin{gathered}
\text { \% flora exótica }=100 \times \text { x } \sum \text { "exóticas"/ } \\
\sum \text { ("exóticas" + "nativas") } \\
\text { \% flora nativa }=100 \times \text { x } \sum \text { "nativas"/ } \\
\sum \text { ("exóticas" + "nativas") }
\end{gathered}
$$

\section{Adaptación de la metodología de la FILAC ${ }^{2}$}

Para contribuir a reforzar el conocimiento y la valoración de la flora no-vascular de la ecorregión subantártica de Magallanes, se adaptó la metodología denominada FILAC (Rozzi et al. 2010) y el marco conceptual de la ética biocultural (Rozzi, 2013). La aproximación metodológica de la FILAC incluye un ciclo de cuatro pasos, cada uno de los cuales fue adaptado en este trabajo (Fig. 2).

\section{Paso I. Investigación transdisciplinaria}

Se realizó un catastro de la flora de musgos, hepáticas y líquenes del circuito interpretativo "Bosques en Miniatura del Cabo de Hornos",

ecorregión subantártica de Magallanes. Tesis de Magíster en Ciencias. Programa de Conservación Biocultural Subantártica. Punta Arenas: Universidad de Magallanes, Chile. 


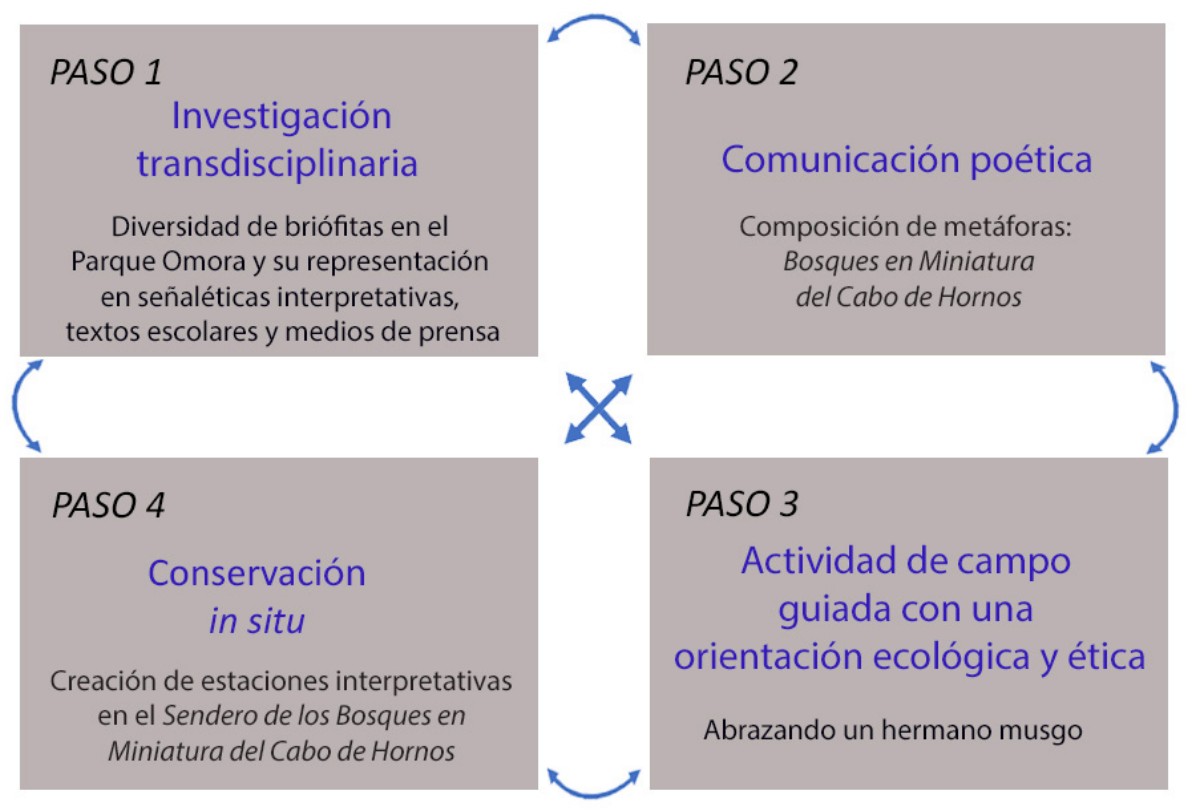

Fig. 2. Representación esquemática del ciclo de cuatro pasos de la Filosofía Ambiental de Campo (FILAC) adaptado en este trabajo. Se ejemplifica cada paso general (azul) con metodologías particulares (negro). El Paso 1 integra la investigación sobre la diversidad de briófitas en el Parque Omora y su representación en señaléticas interpretativas, textos escolares y medios de prensa. El Paso 2 incluye la composición de metáforas como los Bosques en miniatura del Cabo de Hornos para comunicar los valores ecológicos, económicos, estéticos y éticos interrelacionados de las diversas comunidades de briófitas. El Paso 3 incluye actividades de campo orientadas con un sentido ecológico y ético, como Abrazando un hermano musgo o Abrazando un hermano árbol. El Paso 4 se enfoca en poner en práctica el trabajo de conservación, como la implementación de estaciones interpretativas en el sendero interpretativo "Bosques en Miniatura del Cabo de Hornos" en el Parque Omora. Las flechas y líneas indican que las interacciones entre los cuatro pasos son multidireccionales. Figura modificada de Rozzi et al. (2008b).

ubicado en la Zona de Uso Público del Parque Omora (Massardo et al. 2013). Se identificaron especies y tipos de sustrato (corteza, suelo o roca) (Rozzi et al. 2012b). El catastro e identificación de especies se efectuó en colaboración con briólogos y liquenólogos chilenos y extranjeros. Se analizaron textos de ética ambiental y de ética biocultural que valoraran desde distintas perspectivas a las briófitas y a la biodiversidad en general.

Paso II. Composición de metáforas y comunicación a través de relatos simples

En un lenguaje cotidiano y pedagógico comprensible para los preescolares, escolares, educadoras de párvulos, profesores de enseñanza básica y media, y estudiantes de pre y postgrado, se generaron relatos simples $y$ se crearon metáforas que incorporaron los resultados de la investigación.

Paso III. Diseño de experiencias de campo guiadas con un sentido ecológico y ético

En base a los relatos simples y metáforas del Paso 2 se diseñaron actividades de terreno guiadas con un sentido ecológico y ético para escolares, profesores, educadoras de párvulos y asistentes, estudiantes graduados, turistas, público general. En la Tabla 1 se detallan las actividades realizadas entre los años 2009 y 2012, exceptuando las visitas turísticas.

Paso IV. Definición e implementación de áreas de conservación in situ

Se trabajó con un equipo intercultural $e$ interdisciplinario que incluyó la participación del artesano y guía de la Comunidad Indígena Yagán, Germán González, los escultores Paola Vezzani, Daniel Saborit y Rodrigo Molina, el ingeniero civil estructural Andrés Stambuk, los especialistas en ecoturismo y educación ambiental Jorge Chávez y 
Tabla 1. Actividades guiadas con un sentido ético y ecológico para el conocimiento y valoración de la brioflora y líquenes de Cabo de Hornos realizadas en el Parque Omora entre los años 2009 y 2012

\begin{tabular}{ll}
\hline Fecha & $\begin{array}{l}\text { Nombre del taller o } \\
\text { actividad }\end{array}$ \\
\hline Marzo-noviembre & $\begin{array}{l}\text { Taller Omora del } \\
\text { Medioambiente (ACLE) }\end{array}$
\end{tabular}

Junio, agosto, octubre 20092010

Mayo 2009

Mayo 2009

Mayo 2009

Mayo 2009

Junio 2009

Junio 2009

Octubre 2010

Enero 2010 y enero 2011
Talleres de Iniciación en Educación Ambiental

Abrazando un Hermano

Bosques en Miniatura del Cabo de Hornos

Bosques en Miniatura del Cabo de Hornos

Visitas guiadas en el circuito de Los Bosques en Miniatura del Cabo de Hornos

Jardinería y conservación de briofitas y liquenes"

Visita guiada en el circuito de Los Bosques en Miniatura del Cabo de Hornos.

Bosques en Miniatura del Cabo de Hornos

Abrazando un Hermano
Público objetivo

Grupo de escolares de Enseñanza

Básica que asisten al Taller Omora todo

el año y presentan sus trabajos en la

Feria Escolar EXOLORA-CONICYT.

Alumnas de la carrera de Educación

Parvularia de la Universidad de

Magallanes

Educadoras de Párvulos y Asistentes de Atención al Menor, Liceo Donald McIntyre, Jardín Ukika y Jardín Pequeños Colonos.

Educadoras de Párvulos y Asistentes de Atención al Menor del Liceo Donald McIntyre, Jardín Ukika y Jardín Pequeños Colonos.

Alumnos de $5^{\circ}$ y $6^{\circ}$ Año Básico del Liceo Donald McIntyre - Taller Omora del Medioambiente.

Funcionarios de la Armada de Chile, Distrito Naval Beagle, Puerto Williams.

Familia de funcionarios $y / o$ funcionarias de la Armada de Chile.

Familia de funcionarios y/o funcionarias de la Armada de Chile.

Educadoras de Párvulos y Asistentes de Atención al Menor del Liceo Donald McIntyre, Jardín Ukika y Jardín Pequeños Colonos.

Estudiantes universitarios chilenos y extranjeros del Curso Internacional de Filosofía Ambiental de Campo, ofrecido por el Programa de Conservación Biocultural Subantártica, Universidad de Magallanes y University of North Texas (véase Malebrán \& Rozzi, 2018).
Objetivo

Conocer y valorar los ecosistemas de la Reserva de la Biosfera Cabo de Hornos, con énfasis en brioflora.

Conocer y valorar diversos aspectos de la ecología de la ecorregión subantártica de Magallanes, con énfasis en la ética ambiental.

Provocar la observación atenta y sensible o "encuentro directo" para la valoración de musgos, hepáticas $y$ líquenes.

Conocer componentes, ecología e importancia en los ecosistemas de las briofitas y líquenes, incluida su fauna asociada.

Conocer los componentes, ecología e importancia de los Bosques en Miniatura del Cabo de Hornos.

Recorrer el circuito interpretativo de los Bosques en Miniatura del Cabo de Hornos, su biodiversidad, importancia ecológica. Practicar el Ecoturismo con Lupa en el Parque Omora.

Conocer herramientas básicas de jardinería utilizando flora nativa novascular.

Recorrer el circuito interpretativo de los Bosques en Miniatura del Cabo de Hornos, su biodiversidad, importancia ecológica y practicar el Ecoturismo con Lupa en el Parque Omora.

Conocer los componentes, ecología e importancia de los Bosques en Miniatura del Cabo de Hornos.

Provocar acercamiento y comprensión de la coexistencia con el 'otro ser no-humano' a los chilenos y extranjeros que no conocían la región subantártica. 
Flavio Berchez, la brióloga Lily Lewis y las biólogas Manuela Méndez y Kelli Moses, en el diseño y la habilitación de un área de conservación in situ del sendero interpretativo "Bosques en Miniatura del Cabo de Hornos" en el Parque Omora. Este sendero interpretativo tiene un kilómetro de longitud y en su recorrido se puede apreciar la diversidad de "cohabitantes vegetales" (briófitas y líquenes), sus hábitos de vida y los hábitats donde crecen. El circuito incluye 14 estaciones interpretativas con estructuras metálicas en forma de lupa que centran la atención del visitante en especies o comunidades vegetales no-vasculares, $y$ en las características de cada tipo de micro-hábitat y sustrato. En este sendero se practica el "Ecoturismo con Lupa" con distintos tipos de visitantes. Los recorridos y prácticas pueden durar entre una y dos horas en visitas guiadas con turistas, o pueden durar varios días durante los cursos con investigadores y estudiantes o los talleres de formación en ecoturismo.

\section{Evaluación del impacto de las actividades educativas en escolares y medios de comunicación}

El impacto de los talleres realizados con la metodología FILAC se evaluó mediante indicadores asociados a la educación formal y otros asociados a la educación no-formal, y más ampliamente a la cultura regional. El grupo de indicadores de educación formal se evaluó con encuestas estructuradas a escolares de Puerto Williams y el segundo grupo de indicadores de educación noformal se basó en la cuantificación de publicaciones sobre los bosques en miniatura del Cabo de Hornos y/o la actividad de ecoturismo con lupa en la prensa regional (periódico La Prensa Austral), nacional y la difusión a través de internet.

\section{Encuestas a escolares de Puerto Williams}

Se analizaron encuestas estructuradas (sensu Bernard, 1995) diseñadas y aplicadas por Ricardo Rozzi (2002) a 114 estudiantes en el año 2000, y que Yanet Medina volvió a aplicar en el año 2009 a 25 estudiantes del liceo en Puerto Williams. La encuesta es individual, se aplica en sala de clases y se responde por escrito. La identificación requiere: fecha de toma de la encuesta, nombre, lugar y fecha de nacimiento, residencia anterior a
Puerto Williams y tiempo de residencia en la isla Navarino. Incluye tres preguntas relativas a aves y plantas y dos preguntas de desarrollo. En este estudio se analizaron las respuestas escritas para la pregunta Nombra las cinco primeras plantas que recuerdes. Para los análisis se consideró sólo la primera planta mencionada por los estudiantes en sus respuestas a la pregunta anterior.

Complementariamente al trabajo con escolares, se analizó la percepción de preescolares a través de ejercicios de dibujos realizados en el Jardín Infantil Pequeños Colonos. Estos ejercicios se realizaron el año 2009, antes de los talleres sobre "Bosques en Miniatura del Cabo de Hornos" conducidos por Yanet Medina y asistentes de educación parvularia, y el año 2010 después de la realización de estos talleres. Los talleres incluyeron una indagación simple (equivalente al Paso 1 de la FILAC) y la realización de dibujos (como actividad equivalente al Paso 2 de la FILAC). El año 2010 se realizó una actividad en terreno (equivalente al Paso 3 de la FILAC). A través del análisis de los dibujos se evaluó el impacto de los talleres y la efectividad para el aprendizaje y valoración de la biodiversidad de los bosques en miniatura por parte de los párvulos. Finalmente, con los preescolares del liceo se intentó crear un pequeño jardín de bosques en miniatura en el patio de la escuela, como adaptación del Paso 4 de la FILAC.

Por último, con el fin de evaluar el impacto de una experiencia rápida de FILAC asociada a la visita turística al sendero de los "Bosques en Miniatura", durante la temporada 2009-2010 se aplicaron las encuestas antes y después de una visita guiada por Yanet Medina en el Parque Omora. En total se encuestó a 37 turistas, incluyendo visitantes chilenos y extranjeros.

Revisión de la prensa regional, nacional e internacional

Se revisaron todos los ejemplares del periódico regional La Prensa Austral entre los años 2000 y 2009, el único medio escrito de distribución masiva magallánica en esa época. La búsqueda consideró los términos clave "Turismo con Lupa" y "Bosques en Miniatura" en notas, artículos, entrevistas, cartas al director, crónicas, suplementos de turismo y avisos 
publicitarios. Se contabilizó el número de artículos en que alguno de estos dos términos estaba mencionado; si se nombraban en la misma publicación se consideró como una sola mención. Para determinar el número de veces que estos conceptos fueron citados en la prensa nacional, en medios escritos y en internet, se utilizó el buscador Google bajo dos grupos de términos clave: 1) turismo - lupa - Omora, 2) bosques - miniatura - Omora. También se revisaron archivos y registros de prensa del Programa de Conservación Biocultural Subantártica 2000-2009 utilizando las claves: Turismo con Lupa y Bosques en Miniatura asociadas a Parque Omora, Parque Etnobotánico Omora, Fundación Omora y Omora. Para el caso de internet, se utilizó el buscador Google usando grupos de palabras clave en español: turismo - lupa - Omora, bosques - miniatura - Omora, y en inglés: tourism - lens - Omora y miniature - forest - Omora. La información se clasificó por año y por concepto, pudiendo estar uno o más conceptos contenidos en una misma publicación.

\section{RESULTADOS}

Análisis de las ilustraciones de los textos de ciencias naturales para la Educación General Básica y Media

En las ilustraciones de los textos escolares se identificaron 459 tipos de plantas. Para cada tipo de planta se determinó el número de ocurrencias, y se clasificó en las categorías taxonómicas de plantas vasculares y no-vasculares y en las categorías biogeográficas de especies nativas chilenas o exóticas.

\section{Enseñanza Básica}

Se identificaron 316ilustraciones que incluían plantas. Respecto a las categorías taxonómicas, el 98,4\% (311 ilustraciones) correspondió a flora vascular y sólo un 1,6\% (5 ilustraciones) a flora no-vascular (Tabla 2). Respecto a las categorías biogeográficas, el 82,4\% (103 imágenes) de las

Tabla 2. Número y porcentajes relativos de especies de plantas vasculares y no-vasculares ilustradas en imágenes en los textos de $1^{\circ}$ a $8^{\circ}$ años de Enseñanza Básica utilizados en establecimientos de educación pública en Chile el año 2009.

\begin{tabular}{|c|c|c|c|c|c|}
\hline Curso & $\begin{array}{l}\text { Número } \\
\text { de plantas } \\
\text { Vasculares }\end{array}$ & $\begin{array}{c}\text { Número } \\
\text { de plantas } \\
\text { No-vasculares }\end{array}$ & $\begin{array}{c}\text { Total de plantas } \\
\text { Vasculares }+ \\
\text { No-vasculares }\end{array}$ & $\begin{array}{l}\text { Porcentaje relativo } \\
\text { de Vasculares/Total }\end{array}$ & $\begin{array}{c}\text { Porcentaje relativo de No- } \\
\text { vasculares / Total }\end{array}$ \\
\hline $\begin{array}{l}1^{\circ} \text { Año } \\
\text { Básico }\end{array}$ & 71 & 0 & 71 & $100,00 \%$ & $0,00 \%$ \\
\hline $\begin{array}{l}2^{\circ} \text { Año } \\
\text { Básico }\end{array}$ & 86 & 2 & 88 & $97,70 \%$ & $2,30 \%$ \\
\hline $\begin{array}{l}3^{\circ} \text { Año } \\
\text { Básico }\end{array}$ & 50 & 0 & 50 & $100,00 \%$ & $0,00 \%$ \\
\hline $\begin{array}{l}4^{\circ} \text { Año } \\
\text { Básico }\end{array}$ & 25 & 1 & 26 & $96,20 \%$ & $3,80 \%$ \\
\hline $\begin{array}{l}5^{\circ} \text { Año } \\
\text { Básico }\end{array}$ & 29 & 1 & 30 & $96,70 \%$ & $3,30 \%$ \\
\hline $\begin{array}{l}6^{\circ} \text { Año } \\
\text { Básico }\end{array}$ & 21 & 1 & 22 & $95,50 \%$ & $4,50 \%$ \\
\hline $\begin{array}{l}7^{\circ} \text { Año } \\
\text { Básico }\end{array}$ & 15 & 0 & 15 & $100,00 \%$ & $0,00 \%$ \\
\hline $\begin{array}{l}8^{\circ} \text { Año } \\
\text { Básico }\end{array}$ & 14 & 0 & 14 & $100,00 \%$ & $0,00 \%$ \\
\hline Total & 311 & 5 & 316 & $98,40 \%$ & $1,60 \%$ \\
\hline
\end{tabular}


Tabla 3. Número y porcentajes relativos de especies de plantas nativas y exóticas ilustradas en imágenes en los textos de $1^{\circ}$ a $8^{\circ}$ años de Enseñanza Básica utilizados en establecimientos de educación pública en Chile el año 2009.

\begin{tabular}{cccccc}
\hline Curso & $\begin{array}{c}\text { Número } \\
\text { de plantas } \\
\text { Nativas }\end{array}$ & $\begin{array}{c}\text { Número } \\
\text { de plantas } \\
\text { Exóticas }\end{array}$ & $\begin{array}{c}\text { Totales } \\
\text { Nativas }+ \\
\text { Exóticas }\end{array}$ & $\begin{array}{c}\text { Porcentaje relativo } \\
\text { de plantas } \\
\text { Nativas }\end{array}$ & $\begin{array}{c}\text { Porcentaje relativo } \\
\text { de plantas } \\
\text { Exóticas }\end{array}$ \\
\hline $1^{\circ}$ Año Básico & 5 & 22 & 27 & $18,50 \%$ & $81,50 \%$ \\
$2^{\circ}$ Año Básico & 8 & 38 & 46 & $17,40 \%$ & $82,60 \%$ \\
$3^{\circ}$ Año Básico & 1 & 11 & 12 & $8,30 \%$ & $91,70 \%$ \\
$4^{\circ}$ Año Básico & 1 & 5 & 6 & $16,70 \%$ & $83,30 \%$ \\
$5^{\circ}$ Año Básico & 6 & 8 & 14 & $42,90 \%$ & $57,10 \%$ \\
$6^{\circ}$ Año Básico & 1 & 11 & 12 & $8,30 \%$ & $91,70 \%$ \\
$7^{\circ}$ Año Básico & 0 & 2 & 2 & $0,00 \%$ & $100,00 \%$ \\
$8^{\circ}$ Año Básico & 0 & 6 & 6 & $0,00 \%$ & $100,00 \%$ \\
\hline Total & 22 & 103 & 125 & $17,60 \%$ & $82,40 \%$ \\
\hline
\end{tabular}

ilustraciones correspondió a especies de plantas exóticas y sólo un $17,6 \%$ (22 imágenes) a especies de plantas nativas (Tabla 3). Más aún, la flora nativa estuvo completamente ausente de las ilustraciones en textos escolares de $7^{\circ}$ y $8^{\circ}$ Básico (Tabla 3).

\section{Enseñanza Media}

En los textos de Enseñanza Media, se identificaron 143 ilustraciones que incluían plantas. Respecto a las categorías taxonómicas, el 99,3\% (142 ilustraciones) correspondió a plantas vasculares y sólo el $0,7 \%$ (1 ilustración) a plantas no-vasculares (Tabla 4). Aún más, la flora no-vascular estuvo completamente ausente de las ilustraciones en textos escolares entre $2^{\circ}$ y $4^{\circ}$ Medio (Tabla 4).Respecto a las categorías biogeográficas, el 58,5\% (31 imágenes) de las ilustraciones contuvo especies de plantas exóticas y un 41,5\% (22 imágenes) incluyó especies de plantas nativas (Tabla 5).

Aplicación de la metodología FILAC e incorporación de la flora no-vascular en la educación

\section{Paso I. Investigación transdisciplinaria}

Se realizó investigación ecológica y filosófica sobre la flora de musgos, hepáticas y líquenes.

a) Investigación ecológica. Se hizo un levantamiento de la flora no-vascular, identificando la diversidad de especies de briófitas y líquenes más comunes en el área donde se extiende el sendero "Bosques en

Tabla 4. Número y porcentajes relativos de especies de plantas vasculares y no-vasculares ilustradas en imágenes en los textos de $1^{\circ}$ a $4^{\circ}$ años de Enseñanza Media utilizados en establecimientos de educación pública en Chile el año 2009.

\begin{tabular}{cccccc}
\hline Curso & $\begin{array}{c}\text { Número de plantas } \\
\text { Vasculares }\end{array}$ & $\begin{array}{c}\text { Número de } \\
\text { plantas No- } \\
\text { vasculares }\end{array}$ & $\begin{array}{c}\text { Total de plantas } \\
\text { Vasculares + No- } \\
\text { vasculares }\end{array}$ & $\begin{array}{c}\text { Porcentaje relativo } \\
\text { de Vasculares/Total }\end{array}$ & $\begin{array}{c}\text { Porcentaje relativo de } \\
\text { No-vasculares / Total }\end{array}$ \\
\hline $1^{\circ}$ Año Medio & 57 & 1 & 58 & $98,3 \%$ & $1,7 \%$ \\
$2^{\circ}$ Año Medio & 54 & 0 & 54 & $100,0 \%$ & $0,0 \%$ \\
$3^{\circ}$ Año Medio & 21 & 0 & 21 & $100,0 \%$ & $0,0 \%$ \\
$4^{\circ}$ Año Medio & 10 & 0 & 10 & $100,0 \%$ & $0,0 \%$ \\
\hline Total & 142 & 1 & 143 & $99,3 \%$ & $0,7 \%$ \\
\hline
\end{tabular}


Tabla 5. Número y porcentajes relativos de especies de plantas nativas y exóticas ilustradas en imágenes en los textos de $1^{\circ}$ a $4^{\circ}$ años de Enseñanza Media utilizados en establecimientos de educación pública en Chile el año 2009.

\begin{tabular}{cccccc}
\hline Curso & $\begin{array}{c}\text { Número de plantas } \\
\text { Nativas }\end{array}$ & $\begin{array}{c}\text { Número de } \\
\text { plantas Exóticas }\end{array}$ & $\begin{array}{c}\text { Totales Nativas } \\
\text { + Exóticas }\end{array}$ & $\begin{array}{c}\text { Porcentaje relativo de } \\
\text { plantas Nativas }\end{array}$ & $\begin{array}{c}\text { Porcentaje relativo de } \\
\text { plantas Exóticas }\end{array}$ \\
\hline $1^{\circ}$ Año Medio & 3 & 14 & 17 & $17,6 \%$ & $82,4 \%$ \\
$2^{\circ}$ Año Medio & 17 & 10 & 27 & $63,0 \%$ & $37,0 \%$ \\
$3^{\circ}$ Año Medio & 1 & 5 & 6 & $16,7 \%$ & $83,3 \%$ \\
$4^{\circ}$ Año Medio & 1 & 2 & 3 & $33,3 \%$ & $66,7 \%$ \\
\hline Total & 22 & 31 & 53 & $41,5 \%$ & $58,5 \%$ \\
\hline
\end{tabular}

Miniatura del Cabo de Hornos" del Parque Omora. Se identificaron 87 especies: 39 musgos, 7 hepáticas, 2 antocerotes y 39 líquenes (Tabla 6). Para cada especie se describieron los atributos morfológicos básicos y/o singulares, y se caracterizó el sustrato o micro-hábitat, distinguiendo suelo del bosque, corteza de árboles o arbustos, y rocas o piedras.

b) Investigación filosófica. El análisis de los textos de ética ambiental se centró en los trabajos Pensando como una Montaña y La Ética de la Tierra del ecólogo estadounidense Aldo Leopold (2007), Raíces históricas de nuestra crisis ecológica del historiador de la misma nacionalidad Lynn White Jr. (2007) y el análisis comparativo que hace Ricardo Rozzi (2007) de este texto con el Cántico al hermano sol, escrito por Francisco de Asís en el año 1225. Además, se examinó el concepto de co-habitante acuñado por Rozzi (2001, 2013) en su ética biocultural, quien también compara este concepto con el de criaturas hermanas evocado por Francisco de Asís (Boff, 2003, 2006, 2012). Del análisis de estos textos se extrajo el planteamiento de los autores (Tabla 7) y la propuesta reflexiva y espiritual de este trabajo.

Paso II. Composición de metáforas

El análisis del Paso 2 condujo a un acercamiento espiritual hacia los planteamientos de los autores estudiados en el Paso 1. Las actividades en terreno desarrolladas en los talleres educativos (Tabla 1) llevaron a la composición de la metáfora Hermano Musgo. Esta metáfora provoca un acercamiento igualitario de los seres humanos con estas plantas diminutas, otorgándoles un nivel de igualdad, valoración y respeto que apela a la propuesta de Francisco de Asís, quien llama "hermanos" a todos los componentes del universo. La metáfora Hermano Musgo induce un vínculo espiritual entre las personas que la practican con las briófitas y con otros seres que viven en los árboles, quienes también pueden ser considerados como hermanos o co-habitantes.

Paso III. Actividad ecológica y éticamente guiada

Para incentivar el reencuentroy la conciencia de la coexistencia con otros seres vivos, se diseñó una actividad de campo ecológica y éticamente guiada: Abrazando un Hermano. Esta actividad fue registrada en dos documentales: Regreso a la Madriguera, dirigido por Jaime Sepúlveda, periodista y productor nacional, y Conservación Biocultural en el Fin del Mundo, dirigido por Jorge Grez, realizador audiovisual magallánico. Otro documental de la Serie Conservación Biocultural en el Fin del Mundo de UMAG-TV, se basa en la metodología de la FILAC e incluye el caso presentado. Estos trabajos están disponibles en línea en la Videoteca UMAG-Puerto Williams: https://www.youtube.com/embed/

A partir de la actividad Abrazando un Hermano realizada bajo la guía de Yanet Medina con escolares y educadoras de párvulos de Puerto Williams, se obtuvieron resultados cualitativos que se expresan en comentarios de los participantes (Tablas 8 y 9). 
Tabla 6. Listado de las especies de briófitas y líquenes más comunes en el sector del sendero interpretativo de los "Bosques en Miniatura del Cabo de Hornos" en el Parque Omora en los años 2009-2012.

\begin{tabular}{|c|c|c|c|c|}
\hline \multirow{2}{*}{$\mathrm{N}^{\circ}$} & \multirow{2}{*}{ LÍQUENES } & \multicolumn{3}{|l|}{ BRIOFITAS } \\
\hline & & Musgos & Hepáticas & Antocerotes \\
\hline 1 & Calicium viride & Acrocladium auriculatum & Gackstroemia magellanica & Nothoceros fuegiensis \\
\hline 2 & Caloplaca sublobulata & Andreaea regularis & Lepidozia chorulifera & Nothoceros endiviifolius \\
\hline 3 & $\begin{array}{l}\text { Cetraria islándica sub sp. } \\
\text { antarctica }\end{array}$ & Bartramia mossmaniana & Marchantia berteroana & \\
\hline 4 & Cladonia cornuta & Bartramia patens & Metzgeria decipiens & \\
\hline 5 & Cladonia rangiferina & Blindia magellanica & Noteroclada confluens & \\
\hline 6 & Cladonia ustulata & Brachythecium subplicatum & Plagiochila elata & \\
\hline 7 & Coelopogon epiphorellum & Breutelia integrifolia & Syzgiella jacquinotii & \\
\hline 8 & Haematomma erythromma & Catagonium nitens & & \\
\hline 9 & Hypogymnia lugubris & Ceratodon purpureus & & \\
\hline 10 & Leptogium menziesii & Conostomum tetragonum & & \\
\hline 11 & Menegazzia globulifera & Dendroligotrichum squamosum & & \\
\hline 12 & Nephroma antarcticum & Dicranoloma robustum & & \\
\hline 13 & Nephroma parile & Funaria hygrometrica & & \\
\hline 14 & Pannaria contorta & Grimmia trichophylla & & \\
\hline 15 & Parmelia cunninghamii & Hymenodontopsis mnioides & & \\
\hline 16 & Peltigera neopolydactyla & Hypnum skottsbergii & & \\
\hline 17 & Peltigera patagonica & Hypopterygium didictyon & & \\
\hline 18 & Peltigera pulverulenta & Leptostomum menziesii & & \\
\hline 19 & Platismatia glauca & Leptotheca gaudichaudii & & \\
\hline 20 & Porpidia crustulata & Lepyrodon lagurus & & \\
\hline 21 & Protousnea magellanica & Orthotrichum compactum & & \\
\hline 22 & Pseudephebe minuscula & Orthotrichum crassifolium & & \\
\hline 23 & Pseudocyphellaria berberina & Orthotrichum elegantulum & & \\
\hline 24 & Pseudocyphellaria corifolia & Orthotrichum rupestre & & \\
\hline 25 & Pseudocyphellaria crocata & Philonotis vagans & & \\
\hline 26 & Pseudocyphellaria endochrysa & Platyneuron praealtum & & \\
\hline 27 & Pseudocyphellaria freycinetii & Pohlia lonchochaete & & \\
\hline 28 & Pseudocyphellaria granulata & Polytrichadelphus magellanicus & & \\
\hline 29 & Pseudocyphellaria lechleri & Polytrichum strictum & & \\
\hline 30 & Pseudocyphellaria obvoluta & Ptychomnion cygnisetum & & \\
\hline
\end{tabular}


Continuación Tabla 6

\begin{tabular}{lll}
\hline 31 & Ramalina terebrata & Rhynchostegium fuegianum \\
32 & Rhizocarpon geographicum & Sphagnum fimbriatum \\
33 & Sphaerophorus globosus & Sphagnum magellanicum \\
34 & Sticta gaudichaldii & Syntrichia andersonii \\
35 & Sticta hypochra & Tayloria dubyi \\
36 & Thamnolia vermicularis & Tayloria mirabilis \\
37 & Usnea trachycarpa & Tetraplodon fuegianus \\
38 & Verrucaria maura & Ulota magellanica \\
39 & Xanthoria candelaria & Vittia pachyloma \\
\hline
\end{tabular}

Tabla 7. Planteamientos filosóficos y propuestas reflexivas y espirituales.

\begin{tabular}{|c|c|c|}
\hline Autor & Planteamiento filosófico & Propuesta reflexiva y espiritual para este trabajo \\
\hline Aldo Leopold & $\begin{array}{l}\text { La naturaleza como un sistema ecológico al que } \\
\text { pertenecemos. }\end{array}$ & $\begin{array}{l}\text { Apreciar la naturaleza como un sistema vivo al que } \\
\text { pertenecemos. Planeta Tierra, madre que vive y da } \\
\text { vida. }\end{array}$ \\
\hline Lynn White Jr. & $\begin{array}{l}\text { Religarnos con la naturaleza en vez de usarla como } \\
\text { proveedora de "recursos naturales" al servicio del } \\
\text { hombre. }\end{array}$ & $\begin{array}{l}\text { Reencontrarnos con los seres vivos y no-vivos, y por } \\
\text { lo tanto reconocer en ellos a los "otros" con quienes } \\
\text { coexistimos sin que deban estar a nuestro servicio. }\end{array}$ \\
\hline $\begin{array}{l}\text { Francisco de } \\
\text { Asís }\end{array}$ & $\begin{array}{l}\text { Cada componente del universo tiene un valor } \\
\text { individual e igualitario. Todos somos hermanos. }\end{array}$ & $\begin{array}{l}\text { Reconocer en cada componente del universo un } \\
\text { hermano espiritual. Cada elemento, vivo y no-vivo } \\
\text { es un semejante, por lo tanto un hermano por el } \\
\text { que fluye la misma energía que nos mueve a todos, } \\
\text { independiente del credo religioso. }\end{array}$ \\
\hline Ricardo Rozzi & $\begin{array}{l}\text { Vínculo socio-ecológico de cohabitar compartiendo } \\
\text { hábitats comunes y relaciones de parentesco } \\
\text { genealógico o evolutivo. }\end{array}$ & $\begin{array}{l}\text { Valorar los vínculos vitales entre los hábitos de vida y } \\
\text { los hábitats compartidos con diversos co-habitantes } \\
\text { (humanos y otros-que-humanos. }\end{array}$ \\
\hline
\end{tabular}

Paso IV. Conservación in situ

Como resultado del Paso 4 se contribuyó al diseño y habilitación de estaciones interpretativas en el sendero de los "Bosques en Miniatura del Cabo de Hornos" del Parque Omora. El resultado de este paso quedó publicado en el libro ilustrado Ecoturismo con Lupa en el Parque Omora (Rozzi et al. 2012b), que invita a visitar y recorrer el sendero. También se aportó en la preparación del capítulo IV liderado por Lily Lewis en el libro Los Bosques en Miniatura del Cabo de Hornos - Ecoturismo con Lupa (Goffinet et al. 2012), donde se describen las estaciones interpretativas.
Evaluación del impacto en los escolares y en la prensa regional

a) Encuestas a escolares año 2000. Se analizaron 114 entrevistas realizadas a estudiantes del liceo en sus salas de clase. Todos los encuestados eran chilenos, provenientes de ciudades desde la Región de Arica y Parinacota hasta la Región de Magallanes y Antártica Chilena. Los escolares encuestados en el 2000 tenían en promedio 12 años de edad y un tiempo medio de 4 años de residencia en Puerto Williams.

Ante la pregunta Nombra la cinco primeras plantas que recuerdes, los estudiantes mencionaron 
Tabla 8. Comentarios de los alumnos de 4 Año de Enseñanza Media del Liceo Donald McIntyre de Puerto Williams, con relación a la actividad Abrazando un Hermano, y el uso de la metáfora Hermano Musgo.

\begin{tabular}{|c|c|}
\hline Nombre & Comentario \\
\hline Evelyn Díaz & "Porque me di cuenta que sientes igual que yo, te cuidaré Hermano. Eres como yo, somos iguales". \\
\hline Eliseo Hueche & $\begin{array}{l}\text { "Dios creó a los árboles como nuestros hermanos mayores que nos protegen del clima, limpian } \\
\text { nuestro aire y hermosean nuestra vista". }\end{array}$ \\
\hline Karina Levill & $\begin{array}{l}\text { "A los árboles los siento como a mi familia, protectores cálidos, acogedores, un abrazo, un beso tan } \\
\text { acogedor como el cariño que me demuestran mis seres queridos, es lo que sentí al abrazarte hermano } \\
\text { musgo y hermano árbol". }\end{array}$ \\
\hline Evelyn Sanhueza & "Tan fuerte como el amor tan débil como el corazón, pero siempre hace lo mejor. 'El árbo'”. \\
\hline Bernardo López & $\begin{array}{l}\text { "Bueno, nos elegimos por algo, tú estabas solo es un círculo y a mí siempre me gusta acercarme a las } \\
\text { personas que están solas y tú eres una persona, mi hermano". }\end{array}$ \\
\hline Harol Muñoz & "Una caja de secretos y recuerdos. Un hermano". \\
\hline Francisco Villena & "Somos iguales, con la lupa observé vida en ti, como también la hay en mí". \\
\hline Camila Fernández & "Confía en mí, soy igual a un ser humano. Atentamente, el árbol". \\
\hline Ángela Parra & $\begin{array}{l}\text { "El interés está en cada uno, para conocer el propósito de la vida de nuestra biodiversidad en el } \\
\text { mundo. En la vida hay muchas cosas que no conocemos y también hay pureza en lo que no queremos } \\
\text { ver...". }\end{array}$ \\
\hline
\end{tabular}

30 especies en total. Ninguno de ellos mencionó los musgos o alguna briófita o liquen. Todas las plantas mencionadas fueron vasculares (Fig. 3a). El mayor porcentaje de mención lo obtuvieron: con un $17,5 \%$, la rosa (Rosa sp.), un $7 \%$ el manzano (Malus domestica Borkh. 1803), un 5,3\% la margarita (Bellis perennis L. 1753) y otro $5,3 \%$ la forma genérica de crecimiento "enredadera". Los porcentajes de mención para las demás especies o formas genéricas de crecimiento vegetal fueron iguales o inferiores al $4,4 \%$. Las formas genéricas incluyeron la mención a enredaderas, helechos, plantas carnivoras, flor, árbol, hortaliza, cactus y pasto.

Respecto al origen biogeográfico, la mayoría de las plantas mencionadas correspondió a especies exóticas. De las 30 especies mencionadas, 22 (73,3\%) fueron exóticas y $8(26,7 \%)$ nativas. Como destacan Rozzi et al. (2008a), es llamativo que el mayor porcentaje de mención lo obtuvieran la rosa y el manzano (Fig. 3a) que corresponden a dos especies que no crecen en Puerto Williams u otros lugares de la $\mathrm{RBCH}$. Sólo dos especies exóticas ausentes del área acumularon un $25 \%$ de todas las respuestas.

b) Encuestas a escolares año 2009. Se analizaron 25 entrevistas realizadas a estudiantes del liceo en sus salas de clase. Todos los encuestados eran chilenos, provenientes de ciudades desde la Región de Arica y Parinacota hasta la Región de Magallanes y Antártica Chilena. Los escolares encuestados en el 2009 tenían 14 años de edad en promedio con tiempo medio de residencia de un año en Puerto Williams.

Ante la pregunta Nombra las cinco primeras plantas que recuerdes, los 25 estudiantes mencionaron 9 especies en total. Llamativamente los musgos ocupan el segundo lugar en frecuencia de mención. Al igual que el año 2000, el mayor porcentaje de mención fue para la rosa con un $28 \%$, seguida por los musgos (como grupo de plantas) con un 24\%. Luego, la mención al calafate (Berberis buxifolia G. Forst.) fue incluida en un $12 \%$ de las respuestas y el "helecho" (sin especificar especie) en un $8 \%$. Finalmente, la lenga (Nothofagus pumilio (Poepp. \& Endl.) Krasser 1896), el copihue (Lapageria rosea Ruiz \& Pav. 1802), el manzano, la menta (Mentha sp.) y los cactus (como grupo de plantas) fueron mencionados en un $4 \%$ de las respuestas. 
Tabla 9. Comentarios de educadoras de párvulos de Puerto Williams luego de participar en la actividad Abrazando un Hermano.

\begin{tabular}{|c|c|c|}
\hline Comentario & Autora & Establecimiento \\
\hline \multicolumn{3}{|l|}{ Árbol, parte de la vida, de mi vida } \\
\hline \multicolumn{3}{|l|}{ Llenas de color la tierra, } \\
\hline Esperanza, energía. luz, confianza & Evelyn Cisternas Ponce & $\begin{array}{l}\text { Jardin Infantil Pequeños } \\
\text { Colonos }\end{array}$ \\
\hline \multicolumn{3}{|l|}{ Eso pasa por mi mente cuando te recuerdo.... } \\
\hline \multicolumn{3}{|l|}{ Árbol fuente de naturaleza y de vida. } \\
\hline $\begin{array}{l}\text { Él y yo somos muy parecidos, nacemos, vivimos y después nos llega el } \\
\text { momento de partir; pero luego de un largo camino por sobrevivir lo más } \\
\text { bello y hermoso que dejamos: nuestra descendencia. }\end{array}$ & Paola Ampuero Oyarzo & Jardín Infantil Ukika \\
\hline $\begin{array}{l}\text { Árbol que me acogió, abrazó, que pude sentir que el mundo daba } \\
\text { vueltas a nuestro alrededor, solos tú y yo. Que me diste un poco de } \\
\text { ti y me perfumaste con tu fragancia y me acariciaste con tu suavidad. } \\
\text { Gracias. }\end{array}$ & Jenny Machuca Toledo & Jardín Infantil Ukika \\
\hline $\begin{array}{l}\text { La naturaleza no sólo como formas de vida, paisajes hermosos } \\
\text { y conocimientos específicos sino que también como medio para } \\
\text { actividades de crecimiento personal con niños y adultos... }\end{array}$ & Priscilla Proust & $\begin{array}{l}\text { Jardin Infantil Pequeños } \\
\text { Colonos }\end{array}$ \\
\hline $\begin{array}{l}\text { Descubrí la nobleza de un árbol al dejar albergar en sus ramas un } \\
\text { pequeño jardín y sus habitantes. }\end{array}$ & Dionisia Araya Navea & Jardín Infantil Ukika \\
\hline $\begin{array}{l}\text { Árbol que me acogiste entre tus ramas añosas. Despiertas en mí, todos } \\
\text { los recuerdos felices siempre has sido mi confidente-amigo. Espero } \\
\text { cultivar tu amistad incondicional y que me acojas,... el último día. }\end{array}$ & $\begin{array}{l}\text { María Inés Barrientos } \\
\text { Cárcamo }\end{array}$ & $\begin{array}{l}\text { Liceo Donald McIntyre } \\
\text { Griffiths }\end{array}$ \\
\hline \multicolumn{3}{|l|}{ Te abracé con fuerza. } \\
\hline \multicolumn{3}{|l|}{ Y escuchaste en silencio } \\
\hline $\begin{array}{l}\text { Mis alegrías, penas y secretos... } \\
\text { Amigo mío, me sostuviste con ternura, }\end{array}$ & Iris Andrea Barra Castro & $\begin{array}{l}\text { Liceo Donald McIntyre } \\
\text { Griffiths }\end{array}$ \\
\hline \multicolumn{3}{|l|}{ Sólo espero, algún día, poder comprender } \\
\hline \multicolumn{3}{|l|}{ Lo que me querías contar. } \\
\hline $\begin{array}{l}\text { La naturaleza es parte de nuestras vidas. Nacemos, crecemos y vivimos } \\
\text { retroalimentándonos. }\end{array}$ & Marcela Triviño Mayorga & Jardin Infantil Ukika \\
\hline
\end{tabular}

Respecto al origen biogeográfico, las plantas mencionadas correspondieron a especies nativas y exóticas en proporciones similares. De las 9 especies mencionadas, 5 (55,6\%) fueron exóticas y 4 (44,4\%) nativas. La proporción entreespecies nativasy exóticas es aún más similar si se comparan las ocurrencias de menciones. Los musgos, el calafate, los helechos y la lenga totalizan un $48 \%$ de las respuestas. Estas cuatro especies crecen en abundancia en Puerto Williams y otros lugares de la $\mathrm{RBCH}$.

Usando una prueba de homogeneidad de proporciones, se determinó que la diferencia entre las respuestas de los años 2000 y 2009 es estadísticamente significativa (X2=141,5;37gl; $\mathrm{p} \leq 0,05$; año 2000). ( $X 2=17,3 ; 8 \mathrm{gl} ; \mathrm{p} \leq 0,05$; año 2009). Las respuestas obtenidas en el año 2000 difieren significativamente del año 2009 en dos aspectos fundamentales. El año 2000 no se mencionan briófitas y las respuestas están marcadamente sesgadas hacia las especies exóticas. Ambos sesgos se atenúan el año 2009 porque los entrevistados mencionan en forma protagónica a la flora vascular y a las especies nativas. Por lo tanto, se registra un cambio de la percepción de la flora no-vascular y de la flora nativa en los estudiantes del liceo dentro de la primera década de trabajo con la metodología FILAC en el Parque Omora. 

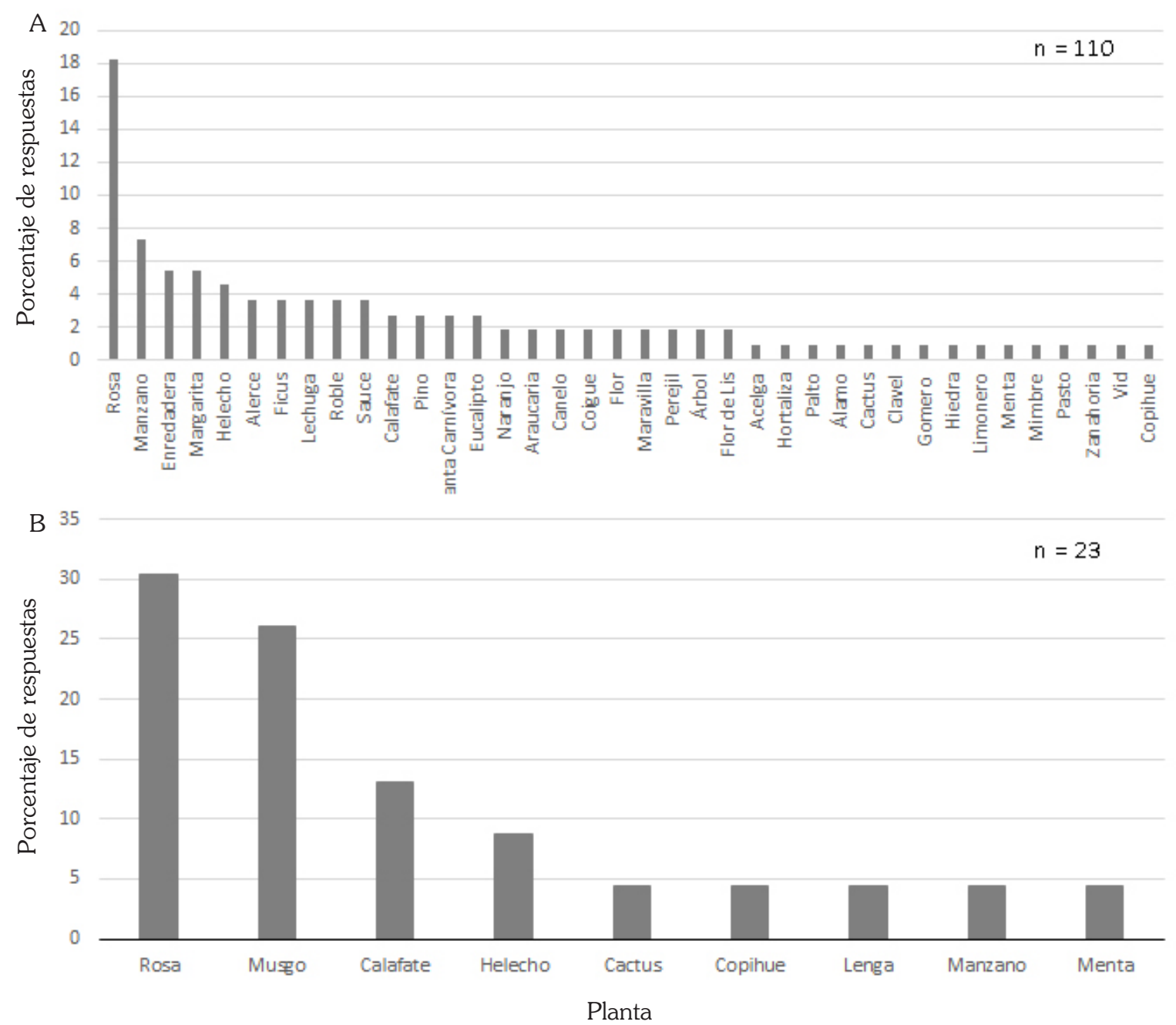

Fig. 3. Respuestas a la encuesta aplicada en los años 2000 (A) y 2009 (B) a escolares del Liceo Donald McIntyre Griffiths de la ciudad de Puerto Williams. Se ilustran los porcentajes relativos del número de veces que fueron mencionadas distintas especies (o categorías genéricas de plantas) ante la pregunta Nombra las cinco primeras plantas que recuerdes.

\section{c) Análisis de dibujos de preescolares.}

En los análisis de los dibujos realizados por 16 preescolares de los niveles de Transición I y II del Jardín Infantil Pequeños Colonos, se identificó que 13 niñas y niños $(81,2 \%)$ no incluyeron imágenes representativas o asociadas con componentes de los Bosques en Miniatura. Sólo 3 dibujos $(18,8 \%)$ manifiestan la inclusión de alguno de tales componentes (Fig. 4). En contraste el año 2010, este grupo de preescolares realizó 14 dibujos, y en 12 de ellos $(85,7 \%)$ había componentes claramente reconocibles de los Bosques en Miniatura, tales como musgos, líquenes o pequeños insectos. Sólo 2 dibujos (14,3\%) carecieron de estos componentes (Fig. 4). Una diferencia relevante respecto al lugar donde se realizaron los dibujos del 2009 y 2010 es que la experiencia del primer año se llevó a cabo en sala, mientras que el segundo año la actividad se complementó con una salida a terreno al área verde frente al jardín infantil. El refuerzo de la actividad 
de terreno se expresa en los resultados obtenidos en los dibujos.

d) Evaluación del Ecoturismo con Lupa en el sendero de los "Bosques en Miniatura del Cabo de Hornos" como forma de educación ambiental. La evaluación de las respuestas de los turistas chilenos y extranjeros acerca de su conocimiento de los conceptos Bosques en Miniatura y Turismo con Lupa, mostró un cambio significativo entre los cuestionarios efectuados antes de recorrer el circuito interpretativo de los Bosques en Miniatura en compañía de la monitora Yanet Medina, y aquellos realizados después de efectuar esta visita guiada (Fig. 5). Antes de la visita guiada sólo un $2,7 \%$ de las respuestas a preguntas relacionadas con los Bosques en Miniatura fue correcto. En cambio, luego de la visita guiada los visitantes demostraron haber comprendido los conceptos y un $73 \%$ de sus respuestas fueron correctas. Análogamente, antes de recorrer el circuito de los "Bosques en Miniatura del Cabo de Hornos" sólo el 2,7\% de los visitantes conocía el concepto de Ecoturismo con Lupa. Luego de recorrer el sendero en compañía del guía el 67,6\% de los visitantes lo había comprendido y respondieron las preguntas correctamente. e) Mención y desarrollo de conceptos en los medios de comunicación regional, nacional e internacional. En el periódico La Prensa Austral, entre los años 2000 y 2009, se encontraron 21 publicaciones que aludían al concepto "Bosques en Miniatura" y 17 que incluían el concepto "Turismo con Lupa”. Entre los años 2000 y 2002 no hubo registros (Fig. 6).

El número de publicaciones nacionales en medios impresos, entre los años 2006 y 2009, fue de 5 con "Bosques en Miniatura" y 7 con "Turismo con Lupa". Entre el 2000 y 2005 no se registraron publicaciones que incluyeran estos conceptos (Fig. 6). En internet de acceso internacional, entre 2003 y 2009 se registraron 118 publicaciones con el concepto "Bosques en Miniatura" y 95 con "Turismo con Lupa". En los años 2000, 2001 y 2002 no se encontraron publicaciones con tales conceptos (Fig. 6).

\section{DISCUSIÓN}

¿Existe un sesgo taxonómico hacia la flora vascular en la educación formal?

El número de plantas vasculares a nivel mundial llega a 300.000 y el número de especies de plantas no-vasculares es de 20.000,

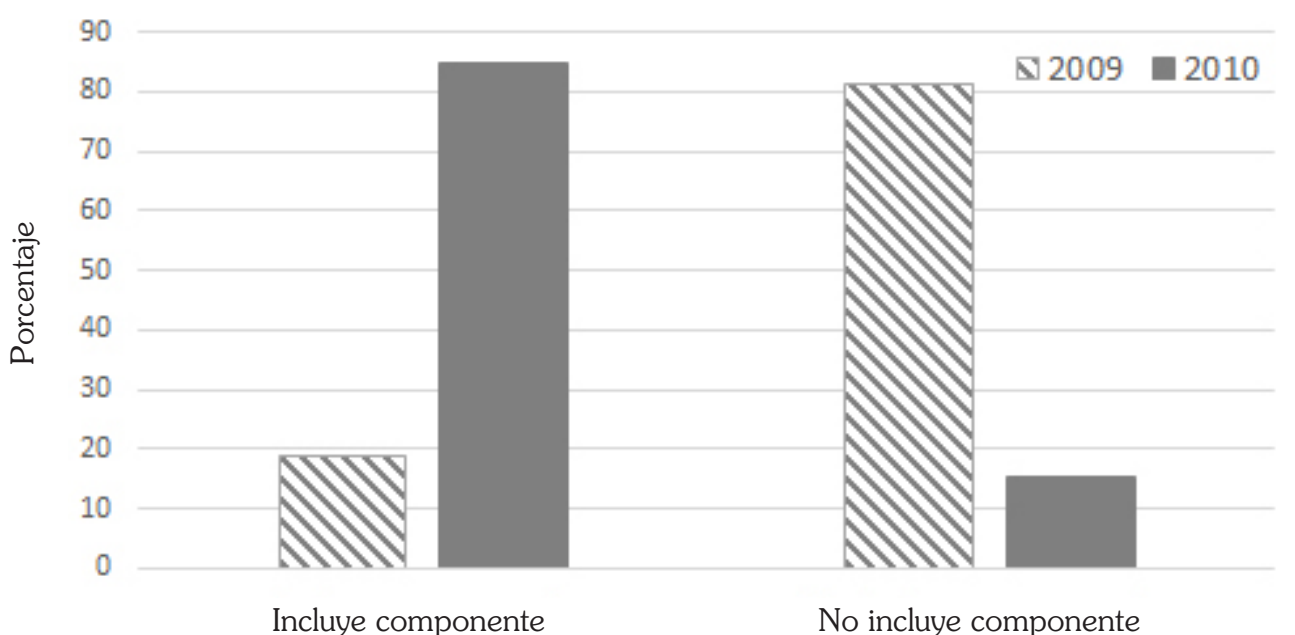

Fig. 4. Porcentaje de dibujos confeccionados por preescolares $(n=30)$ del Jardín Infantil Pequeños Colonos en cuyas composiciones se identifican, o no, componentes de los Bosques en Miniatura (musgos, líquenes o pequeños insectos). Los preescolares confeccionaron sus dibujos en una actividad guiada en sala (año 2009, n=16), y en sala y terreno (año 2010, n=14). 


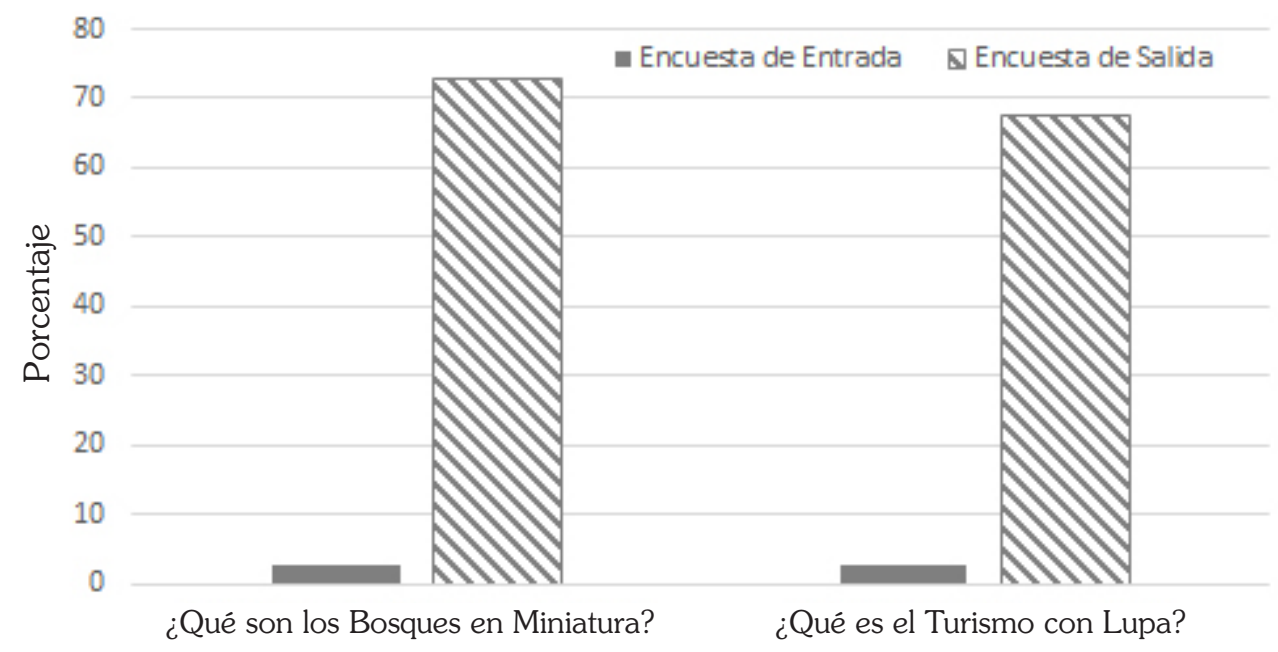

Fig. 5. Porcentaje de respuestas correctas a preguntas asociadas con ¿Qué son los Bosques en Miniatura? y ¿Qué es el Turismo con Lupa? Las barras grises corresponden a los resultados antes de una visita guiada al sendero de los Bosques en Miniatura del Cabo de Hornos en el Parque Omora, y las barras achuradas muestran los resultados expresados en las respuestas después de realizar esta visita guiada.

aproximadamente, es decir, la proporción vascular/ no-vascular es $15: 1$. Se incluyen 12.700 especies de musgos, 6.000 a 8.000 especies de hepáticas y entre 100 y 150 especies de antocerotes (Goffinet \& Shaw, 2009). La ecorregión subantártica de Magallanes posee más del $5 \%$ de todas las briófitas del mundo en un área no superior al 0,01\% de la superficie del planeta (Rozzi et al. 2008b). En contraste con el resto del mundo y de Chile donde predominan las plantas vasculares, en la región de Magallanes predominan las plantas no-vasculares, puesto que existen 818 especies de briófitas versus 773 especies de plantas no-vasculares (Rozzi et al. 2008b). Por el contrario, la flora ilustrada en los textos escolares de Enseñanza Básica incluye casi exclusivamente representaciones de flora vascular (311 imágenes) y omite casi completamente a la flora no-vascular (5 imágenes) (véase Tabla 2). En la Enseñanza Media la prevalencia de la flora vascular en las ilustraciones es aún más marcada, con 142 imágenes versus 1 imagen de la flora novascular (véase Tabla 4). En suma, la proporción de especies no-vasculares/vasculares es de 1,06 en los ecosistemas de la ecorregión subantártica de Magallanes y es de 0,017 y de 0,007 en la flora ilustrada en los textos de ciencias naturales de Enseñanza Básica y Media, respectivamente. Las proporciones de flora no-vascular existente en la realidad biofísica de Magallanes difieren significativamente de aquella representada en los textos escolares de Enseñanza Básica (X2=314,1; $2 \mathrm{gl} ; \mathrm{p} \leq 0,01)$ y Media $(X 2=147,2 ; 1 \mathrm{gl} ; \mathrm{p} \leq 0,05)$. Por lo tanto, se demuestra un marcado sesgo taxonómico en la cultura escolar en favor de las plantas vasculares.

El sesgo en favor de la flora vascular es particularmente problemático en la Región de Magallanes y Antártica Chilena, puesto que se invisibiliza la flora más rica, diversa, singular y por tanto idiosincrática de esta región: la flora no-vascular. Respecto a los sesgos taxonómicos detectados en la educación, es importante considerar que éstos no sólo afectan a la flora sino también a la fauna. A escalas locales, nacionales y globales, se han detectado sesgos que favorecen a los animales vertebrados por sobre los invertebrados (Contador et al. 2018), y dentro de los vertebrados a los endotermos por sobre los ectotermos (Bonnet et al. 2002).

¿Existe un sesgo taxonómico hacia la flora exótica en la educación formal?

El archipiélago Cabo de Hornos es uno de los pocos sistemas insulares subantárticos que está libre de especies de plantas exóticas invasoras (Rozzi et al. 2004). Esta situación de la realidad florística biofísica contrasta con la realidad florística 


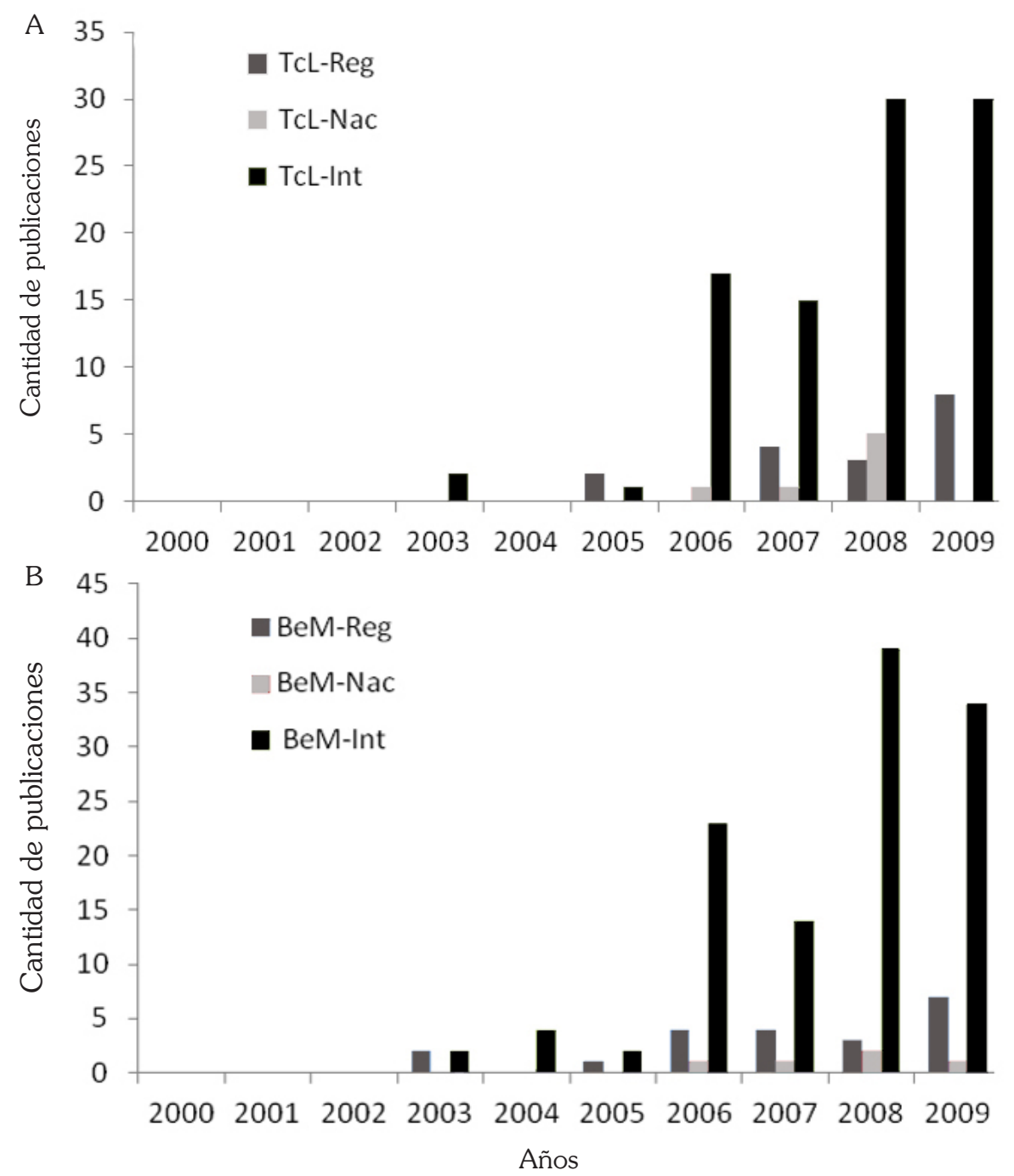

Fig. 6. Número de publicaciones de la prensa regional, nacional e internacional, en las que se hace alusión a los conceptos de (A) Turismo con Lupa (TcL) o (B) Bosques en Miniatura (BeM) en distintos años de la década comprendida entre los años 2000 y 2009. (A) Turismo con Lupa en la prensa regional (TcL-Reg), en la prensa nacional (TcL-Nac) y en la prensa internacional (TcL-Int). (B) Bosques en Miniatura en la prensa regional (BeM-Reg), en la prensa nacional (BeM-Nac) y en la prensa internacional (BeM-Int).

representada en los textos escolares. Los textos de ciencias naturales de Enseñanza Básica del año 2009 incluyeron 103 representaciones de especies de plantas exóticas versus sólo 22 especies nativas (véase Tabla 3). En la Enseñanza Media la prevalencia de la flora exótica se establece con 31 ilustraciones por sobre 22 imágenes de flora nativa (véase Tabla 5). En total, durante su paso escolar los estudiantes de Puerto Williams y otras regiones del país aprenden botánica en base al estudio de 134 ilustraciones (75\%) de especies de plantas exóticas y sólo 44 (25\%) ilustraciones basadas en especies nativas. Esta representación contrasta marcadamente con la flora del archipiélago Cabo de Hornos que está libre de especies de plantas exóticas invasoras. Por lo tanto, se demuestra un marcado sesgo biogeográfico en la cultura escolar en favor de las plantas exóticas.

Este sesgo es particularmente problemático en Magallanes, especialmente el archipiélago Cabo de Hornos, puesto que la educación formal invisibiliza la condición de ser una de las últimas 
áreas "prístinas del planeta" (Rozzi et al. 2006). En el contexto del rápido cambio climático global, y más ampliamente del cambio socio-ambiental global, esta condición del Cabo de Hornos adquiere hoy una relevancia aún mayor para monitorear y proponer medidas de mitigación y adaptación a este cambio.

A escala nacional, el sesgo en favor de las especies exóticas también es problemático. El año 2017 se registraron 2.303.293 matrículas en la enseñanza pública, lo que representa un $86 \%$ de los escolares de Chile (MINEDUC, 2018). Es decir, la mayoría de los estudiantes está expuesta a, y por ende sesgada hacia, la flora exótica durante su formación escolar. Una situación análoga se registra respecto a la fauna, donde se ha registrado una prevalencia de las especies de animales exóticas por sobre las especies nativas en textos escolares de Chile (Celis-Diez et al. 2016) y en el conocimiento de escolares en Argentina (Chediack \& Wehncke, 2002).

A escala global, numerosos estudios han mostrado que existe un sesgo hacia unas pocas especies exóticas en la educación. Por ejemplo, en Francia Jean- Marie Ballouard y colaboradores (2011) examinaron el nivel de conocimiento $y$ preocupación por la diversidad de los animales que los escolares están dispuestos a proteger, y si estas percepciones se guían principalmente por información disponible en internet. Encontraron que el conocimiento de los niños y su interés para proteger a los animales se limitan principalmente al contenido de internet, representados por unas pocas especies exóticas y carismáticas. La tasa de identificación de animales locales por escolares franceses fue muy baja, lo que sugiere una desconexión preocupante de su entorno local. Los estudiantes fueron más propensos a proteger especies "virtuales" (invisibles, exóticas) en lugar de especies animales locales. La conclusión de Ballouard et al. (2011), quienes basan su caso en estudios sobre la fauna, coincide con la nuestra respecto a la relevancia de incluir actividades de campo (Paso 3 de la FILAC) en la educación ambiental, de modo que se pueda desarrollar la conciencia de conservación y las preocupaciones sobre la biodiversidad local.

La descontextualización de la enseñanza de la flora constituye una seria limitación del currículo educativo formal, puesto que, como ocurre en Cabo de Hornos y otras comunas de Chile y el mundo, se enseñan materias que no representan el lugar donde se habita (Morin, 2001; Dussel y Caruso, 2000; Peralta, 2002). El currículo representa una selección de la cultura que se transfiere en la educación y que se refleja en los aprendizajes y la forma en que se realizan (CINDA, 1997). Según Peralta (2006), los niños latinoamericanos conocen más del Sahara o de las estepas africanas que de las llamas del Altiplano, y señala que el currículo debería generarse desde la cultura que valore el patrimonio natural y cultural. Los contenidos entregados deben adecuarse al entorno inmediato y luego a lo regional, nacional y finalmente a lo global, porque ello otorga al estudiante un sentido de pertenencia cultural (Rozzi et al., 1997; Peralta, 2002, 2006).

Los sesgos taxonómicos hacia especies exóticas afectan tanto a los ámbitos de la educación, como de la política y la conservación, puesto que la representación de la biota genera sesgos culturales que exotizan y subvaloran el patrimonio natural y cultural (Paredes-Castellanos \& Rozzi, 2018). Además, se genera una injusticia derivada de un "especiecismo" puesto que la gran mayoría de las publicaciones científicas y políticas sobre conservación se enfoca en especies vasculares y de vertebrados (Rozzi, 2019). Cabe hacer notar que este es el primer trabajo que aborda el sesgo taxonómico hacia las plantas no-vasculares en los textos de estudio en Chile, y junto con el problema presenta una propuesta de solución para la inclusión y valoración de la diversidad de la flora vascular y no-vascular. Esta propuesta metodológica podría ser aplicable en esta región como también en otras regiones del país y del mundo.

\section{FILAC: una aproximación metodológica para superar sesgos taxonómicos en la educación formal y no-formal}

Puerto Williams no está ajena a la globalización y homogeneización que vive hoy el planeta, hecho reflejado en la influencia recibida por los escolares encuestados en 2000 y 2009 que mencionan la especie "rosa" como la primera planta en su imaginario (Fig. 3), que además de ser exótica no crece en dicha ciudad. La rosa representa 
un ícono en la actividad social y cultural; en Roma representaba lujo y sensualidad y en la cultura cristiana tiene significados de carácter religioso (Rozzi et al. 2008a). El protagonismo de esta flor en los estudiantes del liceo más austral de América es un reflejo del que tiene en la cultura europea.

La metodología FILAC aplicada en este trabajo colabora con la integración de las ciencias ecológicas y la ética ambiental en la educación y la conservación biocultural, particularmente a través de experiencias educativas no-formales, tales como el ecoturismo con lupa. Esta particular metodología probó ser efectiva en ámbitos educativos formales y no-formales.

En los ámbitos educativos formales, la FILAC catalizó transformaciones de las apreciaciones sobre la flora tanto en escolares como en preescolares. A nivel de los escolares, el año 2009 se constató una década después de haber incorporado el Taller Permanente Omora del Medioambiente en el currículo escolar del Liceo Donald McIntyre como una Actividad Curricular de Libre Elección (ACLE), que aquéllos incluyeron a los musgos como el segundo grupo de plantas más nombrado. Los musgos (24\%) y las rosas (28\%) totalizaron más del $50 \%$ de las respuestas, mostrando un notable equilibrio o simetría en sus imaginarios bioculturales sobre la flora. Al comparar los resultados de los cuestionarios aplicados a los estudiantes en los años 2000 y 2009 , se demostró un cambio estadísticamente significativo $(\mathrm{X} 2=17,3 ; 8 \mathrm{gl} ; \mathrm{p} \leq 0,05)$. La FILAC incluye ejercicios de composición poética e indagación al aire libre con procesos de indagación en el medio natural que favorecen el conocimiento, la comprensión y el pensamiento crítico por parte de los escolares como han propuesto Arango y colaboradores (2009). Los estudiantes pertenecientes al Taller Omora han participado además en ferias científicas donde han comunicado sus hallazgos sobre la flora no-vascular, es así como el año 2009 obtuvieron el Primer Lugar en la categoría Ciencias del Congreso Científico Escolar del Programa EXPLORA-2009 de CONICYT, con el trabajo "Cobertura y Riqueza de Musgos Epífitos en los Bosques Subantárticos de la Reserva de Biosfera Cabo de Hornos (55²)" (Medina, 2013).

A nivel preescolar, la efectividad de la FILAC quedó demostrada a través de la

3 Investigadora gallega en filosofía y ciencias de la educación que dirige la Cátedra Unesco de Educación Ambiental combinación de los pasos 1,2 y 3 del ciclo de cuatro pasos. Los resultados obtenidos con los párvulos y expresados en sus dibujos fueron producto de una combinación de actividades de indagación, composición pictórica, trabajo al aire libre y de "encuentros directos" con los musgos (sensu Rozzi et al. 2014), logrando que el 85,7\% de los dibujos de los preescolares incluyera representaciones reconocibles de los Bosques en Miniatura, cuadruplicando el resultado obtenido sólo con un ejercicio parcial basado en el Paso 2 de la FILAC. María Novo Villaverde $(2005)^{3}$ ha resaltado la importancia crítica que tiene invitar a las niñas y niños a tener experiencias auténticas donde sean partícipes activos y hagan sus propias observaciones, siendo constructores de sus propios aprendizajes. Nuestros resultados demuestran que en la sala de clases y con la proyección de imágenes no se permite vivir la experiencia de tocar, oler, observar colores, texturas, además de no dimensionar el tamaño real de lo que se observa. Los preescolares sufren una limitación de la realidad que luego se ve plasmada en sus dibujos. En cambio, al vivir la experiencia in situ al aire libre, las niñas y niños recuerdan los componentes de los Bosques en Miniatura que representan claramente en sus dibujos. Esto se debe a que el juego colectivo es otra forma de aprender y puede catalizar la construcción de teorías y valoraciones éticas (Novo, 2006; Tonucci, 2006; Méndez et al. 2018).

En los ámbitos educativos no-formales, la FILAC catalizó cambios culturales que contribuyen al cuidado de la biodiversidad por parte de la ciudadanía a través de experiencias de ecoturismo y de comunicación en los medios de prensa. En el ecoturismo hemos creado una actividad educativa no-formal (el ecoturismo con lupa) que provoca la menor perturbación posible en áreas destinadas para la conservación (como el Parque Omora) y en espacios habilitados (como el sendero de los Bosques en Miniatura) para la recreación controlada. La creación del ecoturismo con lupa es relevante, porque en países como Brasil donde el ecoturismo surgió como una propuesta de contemplación y conservación de la naturaleza (y es una actividad económica en expansión), se han dado voces de alerta para que la educación

y Desarrollo Sostenible en la Universidad Nacional de Educación a Distancia (UNED) de España. 
ambiental sea incluida en el ecoturismo con el fin que efectivamente traiga los beneficios esperados (Davenport et al. 2002; Costa \& Costa, 2005).

Paradójicamente, el aumento del ecoturismo en Brasil y otros lugares no ha sido acompañado por el desarrollo de la práctica educativa; sin embargo, esta opción todavía es viable (Bacchi, 2013). Por ejemplo, un estudio basado en cuestionarios a turistas en el Parque Estadual da Serra do Mar, una de las principales atracciones de ecoturismo en el estado de Sao Paulo con visitas que incluyen senderismo y rafting en el río Paraibuna, siempre acompañadas por monitores, demostró que la gran mayoría de los visitantes está abierta a la educación ambiental y a aprender algo nuevo sobre la naturaleza (Bacchi, 2013). Nuestro estudio en el sendero de los "Bosques en Miniatura del Cabo de Hornos" constituye un aporte para la conservación de las comunidades de brioflora y de líquenes, y ofrece un espacio para hacer educación basada en la ética ambiental. La actividad del Ecoturismo con Lupa en este sendero catalizó cambios en los conocimientos y la valoración de la flora novascular y líquenes en la $\mathrm{RBCH}$.

Los resultados de nuestros cuestionarios indican que es esencial que el visitante tenga un papel activo en la visita y que ello sea fomentado por los guías que orientan la participación de los visitantes en forma ecológica y éticamente responsable. Además, es fundamental incluir el componente lúdico (Berchez et al. 2007, 2015). Al iniciar el recorrido, el guía entrega a cada visitante una lupa de mano y una lupa profesional, transformándolos en actores activos a quienes se invita a descubrir por ellos mismos la diversidad de formas, texturas y colores de sus componentes. La mayoría de los visitantes encuestados desconocía los conceptos o metáforas (Bosques en Miniatura y Ecoturismo con Lupa) al inicio del recorrido, pero luego de la experiencia de campo en compañía de un guía, sus percepciones cambiaron radicalmente (Fig. 5). El ecoturismo con lupa provoca experiencias que permiten a los visitantes vivenciar in situ la existencia y co-habitación con diversos seres vivos, que por lo general están excluidos de los ámbitos considerados en la educación formal y la toma de decisiones (Rozzi et al. 2008a, 2014). Nuestro trabajo documenta que la integración de la educación ambiental en el ecoturismo puede conducir a transformaciones culturales deseadas. Con la aproximación metodológica de la FILAC se ha logrado potenciar el aprecio por el valor intrínseco de la biodiversidad, gatillar cambios en las percepciones y actitudes de los visitantes con una actividad que tiene muy bajo impacto ambiental y huella de carbono al realizarse pausadamente y en un área pequeña. Finalmente, el ecoturismo con lupa ha diversificado la oferta turística conllevando beneficios económicos a través de la prolongación de la estadía de los visitantes y la exaltación de una singularidad del patrimonio natural de Cabo de Hornos (Rozzi et al. 2010b).

En los ámbitos educativos no-formales asociados a los medios de comunicación, la FILAC tuvo un impacto efectivo a través de la creación de las metáforas de los Bosques en Miniatura y del Ecoturismo o Turismo con Lupa. Incorporar nuevos conceptos en el vocabulario cotidiano, incluyendo a la gran mayoría de las personas que son ajenas a la ciencia, permitió que la ciudadanía aumentara su conocimiento y aprecio por la pequeña, pero relevante, flora no-vascular. Este logro, a través del Paso 2 de la FILAC, refuerza la propuesta que para comunicar los descubrimientos científicos en forma simple y directa a la comunidad no científica las metáforas representan efectivos mensajeros culturales que resuenan intensamente y durante mucho tiempo en la sociedad (Rozzi, 1999). Las metáforas integran además hechos y valores (Rozzi, 1999; Larson, 2006; Crego et al. 2018; Malebrán \& Rozzi, 2018). Los resultados obtenidos (Fig. 6) muestran un aumento progresivo de la presencia de metáforas de los Bosques en Miniatura y del Ecoturismo con Lupa en noticias, entrevistas y notas de prensa en la década 2000-2009. Se han incorporado poco a poco en el lenguaje público, con conceptos que han migrado desde un lenguaje técnico, que pocos entienden, hacia un lenguaje simple de muchos (sensu Calvo, 1992). Las metáforas y las adaptaciones de la metodología FILAC y actividades desarrolladas en este trabajo procuran contribuir a la conservación biocultural, la educación y el ecoturismo a través de la habilitación de espacios interpretativos como el sendero de los "Bosques en Miniatura del Cabo de Hornos". Esta simbiosis de conservación biocultural, educación y ecoturismo ha puesto en valor a la diminuta flora no-vascular, un patrimonio natural poco 
conocido y, sin embargo, el más idiosincrático de la ecorregión subantártica de Magallanes y único a nivel mundial. A través de la metodología de la FILAC, los investigadores han logrado transmitir el conocimiento de la flora no-vascular hacia la comunidad, y con metáforas que han apelado a la prensa local, nacional e internacional que las ha considerado interesantes y atractivas para publicar.

\section{CONCLUSIONES}

Este trabajo demuestra cuantitativa $y$ cualitativamente la existencia de un sesgo taxonómico hacia la flora vascular y de un sesgo biogeográfico hacia la flora exótica en los textos de ciencias naturales utilizados en la educación pública en Chile, lo que se detectó también en los imaginarios de los estudiantes del liceo más austral del país y del mundo. Complementariamente, ha evaluado a la metodología FILAC y ha demostrado su efectividad para revertir estos sesgos. A través de la adaptación de esta metodología para el diseño de actividades y conceptos enfocados en la flora no-vascular de la ecorregión subantártica de Magallanes, las metáforas Turismo con Lupa $y$ Bosques en Miniatura se han incorporado progresivamente en la prensa regional, nacional e internacional durante el período 2000-2009. Por medio de la creación del Taller Omora del Medioambiente en el liceo de Puerto Williams, los estudiantes han practicado la FILAC a través de ejercicios de composición poética e indagación al aire libre, han participado en ferias científicas donde han comunicado sus hallazgos sobre la flora no-vascular, han obtenido reconocimientos y una disciplina que a varios de ellos les ha permitido llegar a ser profesionales en áreas medioambientales. La efectividad de la FILAC combinando actividades de indagación, composición pictórica, trabajo al aire libre y de "encuentros directos" con los diversos seres vivos, fue particularmente relevante para los preescolares. Finalmente, la FILAC catalizó cambios culturales que contribuyen al cuidado de la biodiversidad por parte de la ciudadanía, a través de experiencias de ecoturismo. Este trabajo demuestra que es posible catalizar transformaciones bioculturales que generen cambios en la percepción y valoración de seres vivos, que a menudo pasan inadvertidos. A través de la aproximación metodológica de la FILAC, musgos, hepáticas y líquenes han llegado a ser hoy visibles y conocidos por su valor ecológico, ético, estético y económico, pero principalmente por su valor intrínseco. Este trabajo realizado por el Programa de Conservación Biocultural Subantártica podría ser adoptado y adaptado en otros sitios de estudios socio-ecológicos para contribuir a visibilizar, valorar y conservar miríadas de seres vivos poco percibidos que son idiosincráticos de otras regiones del planeta, y para recuperar la conexión y el respeto que hemos perdido con los otros-que-humanos.

\section{AGRADECIMIENTOS}

Los autores agradecen a los profesores y estudiantes del Liceo Donald McIntyre Griffiths, especialmente a los participantes del Taller Omora. Agradecemos también a las educadoras de párvulos de Puerto Williams, particularmente a quienes participaron en la actividad Abrazando un Hermano Musgo o Árbol, Paola Ampuero Oyarzo, Dionisia Araya Navea, Evelyn Cisternas Ponce, Iris Andrea Barra Castro, María Inés Barrientos Cárcamo, Jenny Machuca Toledo, Priscilla Proust y Marcela Triviño Mayorga. A Mirna Pizarro de la Universidad de Magallanes y Jessica Bak. Al artesano y guía de la Comunidad Indígena Yagán Germán González, a los escultores Rodrigo Molina, Daniel Saborit y Paola Vezzani, al ingeniero civil Andrés Stambuk, a los especialistas en ecoturismo y educación ambiental Jorge Chávez y Flavio Berchez, a los liquenólogos Leopoldo García-Sancho (Universidad Complutense de Madrid), Antonio Gómez Bolea (Universidad de Barcelona) y Javier Etayo (Universidad de Navarra), los briólogos Bernard Goffinet (University of Connecticut), Shaun Russell (Bangor University) y Lily Lewis (University of Florida), a las biólogas Paula Caballero (Instituto de Ecología y Biodiversidad, IEB), Manuela Méndez (P. Universidad Católica) y Kelli Moses (Universidad de Magallanes, UMAG) y el apoyo institucional de Jennifer Torres (IEB y UMAG). Yanet Medina recibió una beca de Magíster del IEB. Para el trabajo final de este artículo, Francisca Massardo y Ricardo Rozzi agradecen el apoyo del Proyecto de la Agencia Nacional de Investigación de Chile 
(ANID, AFB170008) a través del IEB, y a la Red de Investigación en Ambientes Extremos (NEXER) a través de UMAG. Esta es una contribución del Programa de Conservación Biocultural Subantártica, conjuntamente coordinado por Fundación Omora y UMAG en Chile y University of North Texas, EE.UU.

\section{BIBLIOGRAFÍA}

Arango, N., Chaves, M. E., \& Feinsinger, P. (2009). Principios y Práctica de la Enseñanza de Ecología en el Patio de la Escuela. Santiago, Chile: Instituto de Ecología y Biodiversidad-Fundación Senda Darwin.

Bacchi, R. (2013). A educação ambiental no ecoturismo: um estudo de caso no Parque Estadual da Serra do Mar, Núcleo Santa Virgínia, São Paulo-SP. Tesis de Magíster en Ciencias, Ecología Aplicada. Universidad de Sao Paulo, Piracicaba, Brasil.

Ballouard, J. M., Brischoux, F., \& Bonnet, X. (2011). Children prioritize virtual exotic biodiversity over local biodiversity. PLoS One, 6, 1-8.

Berchez, F., Ghilardi, N., Robim, M., Gusmão, A., Hadel, V., Fluckiger, G., Simões, M., Mazzaro, R., Klausener, C., Sanches, C., \& Bespalec, P. (2007). Projeto trilha subaquática: sugestão de diretrizes para a criação de modelos de educação ambiental em unidades de conservação ligadas a ecossistemas marinos. OLAM Ciência \& Tecnologia Rio Claro/SP, Brasil Ano VII 7(3), 181-209. www.olam.com.br

Berchez, F., Mansilla, A., Ghilardi-Lopes, N.P., Schwindt, E., Leite, K., \& Rozzi, R. (2015). Ecology and education in marine protected areas: Insights from Brazil and South America. In R. Rozzi, F. S. Chapin, J. B. Callicott, S. T. A. Pickett, M. E. Power, J. J. Armesto \& R. H. May Jr. (Eds.), Earth Stewardship: Linking Ecology and Ethics in Theory and Practice (pp. 351-366). Springer, Dordrecht: Netherlands.

Berghoefer, U., Rozzi, R., \& Jax, K. (2008). Local versus Global Knowledge: Diverse Perspectives on Nature in the Cape Horn Biosphere Reserve. Environmental Ethics, 30(3), 273-294.

Bernard, H. R. (1995). Research Methods in Anthropology. Qualitative and quantitative approaches. Walnut Creek: Altamira Press, Inc.

Boff, L. (2003). ¿Qué es el espíritu? Disponible en http:// leonardoboff.com/site-esp/vista/2003/nov14.htm

Boff, L. (2006). Ecología, Grito de la Tierra, Grito de los Pobres. Madrid. Impresiones Trotta.
Boff, L. (2012). La dimensión de lo profundo, el espíritu y la espiritualidad. Disponible en http://conlupalarevista. com.mx/escritorio-del-editor/34092-la-dimension-delo-profundo-el-espiritu-y-la-espiritualidad.html

Bonnet, X., Shine, R., \& Lourdais, O. (2002). Taxonomic chauvinism. Trends in Ecology \& Evolution, 17, 1-3.

Calvo, H. M. (1992). Periodismo Científico. 2a edición. Madrid: Editorial Paraninfo.

Carrero de Blanco, A., \& García Tovar, M. (2008). Programa educativo ambiental para las poblaciones de la zona costera del Estado Miranda. Revista de Investigación, 63, 125-152.

Castro, V. (2007). A propósito de Raíces históricas de nuestra crisis ecológica: Cuarenta años después, ¿qué hay de nuevo? Edición especial: Ética Ambiental. Ambiente y Desarrollo, 21, 95-97.

Celis-Diez, J. L., Díaz-Forestier, J., Márquez-García, M., Lazzarino, S., Rozzi, R., \& Armesto, J. J. (2016). Biodiversity knowledge loss in children's books and textbooks. Frontiers in Ecology and the Environment, 14(8), 408-410.

Chediack, S., \& Wehncke, E. (2002). Diferencias en el Conocimiento de las Plantas y Animales Silvestres Útiles entre los Niños de La Sierra de San Javier, Tucumán, Argentina. Revista Vida Silvestre Neotropical, 11, $1-2$.

CINDA. (1997). Centro interuniversitario de desarrollo. Programa de intercambio universitario entre la Unión Europea y América Latina-Alfa. Gestión Docente Universitaria: Modelos Comparados. Volumen $\mathrm{N}^{\circ} 2$.

Comité Técnico Asesor del Diálogo Nacional sobre la Modernización de la Educación Chilena. (1994). Los desafíos de la educación chilena frente al siglo 21. Santiago, Chile: Editorial Universitaria.

Contador, T., Rozzi, R., Kennedy, J., Massardo, F., Ojeda, J., Caballero, P., Medina, Y., \& Lazzarino, S. (2018). Sumergidos con lupa en los ríos del cabo de Hornos: Valoración ética de los ecosistemas dulceacuícolas y sus co-habitantes. Magallania, 46(1), 183-206.

Costa, N., \& Costa, V.C. (2005). Educação ambiental pelo ecoturismo em unidades de conservação: uma proposta efetiva para o Parque Estadual da Pedra Branca (PEPB) - RJ. En A.G. Pedrini (Ed.). Ecoturismo e educação ambiental (pp. 39-65). Rio de Janeiro: Papel Virtual

Crego, R. D., Ward, N., Jiménez, J., Massardo, F., \& Rozzi, R. (2018). Los ojos del árbol: percibiendo, registrando, comprendiendo y contrarrestando las invasiones biológicas en tiempos de rápida homogeneización 
biocultural. Magallania, 46(1), 137-153.

Davenport, L., Brockelman, W., Wright, P., Ruf, K., \& Valle, F. (2002). Ferramentas de ecoturismo para parques. En J. Terborgh, V. S. C. et al. (Eds.), Tornando os parques eficientes: estratégias para a conservação $d a$ natureza nos trópicos (pp. 305-333). Curitiba: Ed.da UFPR/ Fundação OBoticário.

Dussel, I., Marcelo, C. (2000) La invención del aula: Una genealogía de las formas de enseñar. Buenos Aires, Argentina: Santillana.

Feinsinger, P. (1987). Professional ecologists and the education of young children. Trends in Ecology \& Evolution, 2(2), 51-52.

Feinsinger, P., Margutti, L., \& Oviedo, R. D. (1997). School yards and nature trails: ecology education outside the university. Trends in Ecology \& Evolution, 12(3), 115-120.

Freire, P. (1973) Pedagogía del oprimido. Buenos Aires, Argentina: Siglo XXI.

Freire, P. (1993). Pedagogía de la esperanza: un reencuentro con la pedagogía del oprimido. Ciudad de México, México: Siglo XXI.

Goffinet, B., \& Shaw, A.J. (2009). Bryophyte Biology. Segunda Edición. Cambridge University Press.

Goffinet, B., R. Rozzi, L. Lewis, W. Buck, F. Massardo. (2012). The Miniature Forests of Cape Horn: Eco-Tourism with a Hand-lens ("Los Bosques en Miniatura del Cabo de Hornos: Ecoturismo con Lupa"). Bilingual English-Spanish edition. UNT Press - Ediciones Universidad de Magallanes, Denton TX and Punta Arenas, Chile.

González, C., Martínez, M. T., \& Martínez, C. (2009). La Educación científica como apoyo a la movilidad social: desafíos en torno al rol del profesor secundario en la implementación de la indagación científica como enfoque pedagógico. Estudios Pedagógicos, 25, 6378.

Hargrove, E. (1997). Ética ambiental y educación ambiental. Translation of "Environmental ethics and environmental education" by Eugene Hargrove, Ambiente y Desarrollo, XIII, 47-51.

Hargrove, E. (2008). A traditional and multicultural approach to environmental ethics at primary and secondary school levels. Environmental Ethics, 30, 263-271.

Harlen, W. (2002). Evaluar la alfabetización científica en el programa de la OECD para la evaluación internacional de estudiantes (PISA). Enseñanza de las Ciencias, 20(2), 209-216.

INE (Instituto Nacional de Estadísticas de Chile). (2017).
Resultados del censo 2017. http://resultados. censo2017.cl/Region?R=R12

Larson, B. M. H. (2006). The social resonance of competitive and progressive evolutionary metaphors. BioScience, 56(12), 998-1004.

Leff, E. (2012). Latin American environmental thinking: a heritage of knowledge for sustainability. Environmental Ethics, 34(4), 431-450.

Leopold, A. (2007). Pensando como una montaña. En Ambiente y Desarrollo, Edición especial "Ética Ambiental". Ambiente y Desarrollo, 21, 13-15.

Lewis, L., Gottschalk-Druschke, C., Saldías, C., Mackenzie, R., Malebrán, J., Goffinet, B., \& Rozzi, R. (2018). Cultivando un jardín de nombres en los bosques en miniatura del Cabo de Hornos: extensión de la conservación biocultural y la ética a seres vivos poco percibidos. Magallania, 46(1), 103-123.

Malebrán, J., \& Rozzi, R. (2018). Análisis de los cursos de filosofía ambiental de campo en el Parque Etnobotánico Omora, Reserva de la Biosfera Cabo de Hornos, Chile. Magallania, 46(1), 207-225.

Massardo, F. et al. (2013). Plan de Manejo del Parque Etnobotánico Omora. Punta Arenas: Universidad de Magallanes-Fundación Omora.

Medina, Y. (2013). Bosques en miniatura del Cabo de Hornos: el turismo con lupa como herramienta para la educación, conservación y turismo científico en la ecorregión subantártica de Magallanes. Tesis de Magister en Ciencias. Programa de Conservación Biocultural Subantártica. Punta Arenas: Universidad de Magallanes, Chile.

Méndez, M. O., Cavieres, L., \& Rozzi, R. (2018). Jardineras subantárticas: conocimiento y valoración de la flora altoandina. Magallania, 46(1), 125-135.

MINEDUC. (2018). Análisis de variación de establecimientos educacionales y matrícula en educación escolar de 2016 a 2018. Santiago: Centro de Estudios MINEDUC, Minuta $\mathrm{N}^{\circ} 04$.

Morin, E. (2001). Los siete saberes necesarios para la educación del futuro. Paidós Studio. Barcelona. Disponible en línea en: http://www.slideshare.net/lilianaariasdelgado/20de-octubre2

Novo, M. (2005). Educación ambiental y educación no formal: dos realidades que se realimentan. Revista de Educación, 338, 145-165.

Novo, M. (2006). Educación ambiental, desarrollo sostenible y globalización. Revista de Educación Ambiental, 4(6), 24-30.

Nuño-Mayer, A. (2017). Educar Para la Libertad y la 
Creatividad. Ciudad de México: Secretaría de Educación Pública de México.

Ojeda, J., Rozzi, R., Rosenfeld, S., Contador, T., Massardo, F., Malebrán, J., \& Mansilla, A. (2018). Interacciones bioculturales del pueblo yagán con las macroalgas y moluscos: una aproximación desde la filosofía ambiental de campo. Magallania, 46(1), 155-181.

Paredes-Castellanos, A., \& Rozzi, R. (2018). Homogeneización biocultural: exotización del paisaje femenino latinoamericano. Magallania, 46(1), 237-248.

Peralta, M. V. (2002). Cuadernillos para la reflexión pedagógica. Atendiendo la diversidad. Disponible en línea en: http://www.mineduc.cl/usuarios/parvularia/ doc/201307121714440.1641_DIVERSIDADRGB. pdf

Peralta, M. V. (2006). América Latina "En la educación nos jugamos el futuro": ¿Qué cultura estamos legitimando en nuestras aulas? Revista Envío, número 290, mayo de 2006. Disponible en línea en http://www.envio. org.ni/articulo/3263

Poole, A. K., Hargrove, E., Day, C., Forbes, W., Berkowitz, A., Feinsinger, P., \& Rozzi, R. (2013). A call for ethics literacy in environmental education. In R. Rozzi, S. T. A. Pickett, C. Palmer, J. J. Armesto, \& J. B. Callicott (Eds.). Linking Ecology and Ethics for a Changing World: Values, Philosophy, and Action. Ecology and Ethics Series (pp. 349-372). Dordrecht: Springer.

Rozzi, R. (1999). The reciprocal link between evolutionaryecological sciences and environmental ethics. BioScience, 49, 911-921.

Rozzi, R. (2001). Éticas ambientales latinoamericanas: raíces y ramas. En R. Primack, R. Rozzi, P. Feinsinger, R. Dirzo, \& F. Massardo. Fundamentos de conservación biológica: perspectivas latinoamericanas (pp. 311362). México: Fondo de Cultura Económica.

Rozzi, R. (2002). Biological and cultural conservation in the archipelago forest ecosystems of southern Chile. Department of Ecology and Evolutionary Biology, University of Connecticut, USA. Ph.D. Dissertation.

Rozzi, R. 2007. Las raíces históricas de nuestra crisis ecológica: Seres vivos más que "recursos naturales". Ambiente y Desarrollo, XXIII, 87-89.

Rozzi, R. (2013). Biocultural ethics: From biocultural homogenization toward biocultural conservation. In R. Rozzi, S.T.A. Pickett, C. Palmer, J.J. Armesto \& J.B. Callicott (Eds.), Linking Ecology and Ethics for a Changing World: Values, Philosophy, and Action. Ecology and Ethics book series, vol 1 (pp. 9-32). Springer, Dordrecht: Netherlands.
Rozzi, R. (2019). Taxonomic Chauvinism, no More! Antidotes from Hume, Darwin, and Biocultural Ethics. Environmental Ethics, 41(3), 253-288.

Rozzi, R., P. Feinsinger, R. Riveros. 1997. La Enseñanza de la Ecología en el Entorno Cotidiano. Módulo de Educación Ambiental. Ministerio de Educación de Chile, Santiago, Chile

Rozzi, R., Charlin, R., Ippi, S., \& Dollenz, O. (2004). Cabo de Hornos: un parque nacional libre de especies exóticas en el confín de América. Anales del Instituto de la Patagonia, 32, 55-62.

Rozzi, R., Massardo, F., Anderson, C. B., Heidinger, K., \& Silander, J. Jr. (2006). Ten principles for biocultural conservation at the southern tip of the Americas: the approach of the Omora Ethnobotanical Park. Ecology \& Society, 11(1), http://apps.isiknowledge.com/full_ record.do?product=WOS\&search_mode $=$ Genera

Rozzi, R., Arango, X., Massardo, F., Anderson, C. B., Heidinger, K., \& Moses, K. (2008a). Field environmental philosophy and biocultural conservation: The Omora Ethnobotanical Park educational program. Environmental Ethics, 30(3), 325-336.

Rozzi, R., Armesto, J. J., Goffinet, B., Buck, W., Massardo, F., Silander, J. et al. (2008b). Changing lenses to assess biodiversity: patterns of species richness in sub-Antarctic plants and implications for global conservation. Frontiers in Ecology and Environment, 6(3), 131-137.

Rozzi, R., Anderson, C. B., Pizarro, J. C., Massardo, F., Medina, Y., Mansilla, A. O., ... \& Kalin, M. T. (2010a). Filosofía ambiental de campo y conservación biocultural en el Parque Etnobotánico Omora: Aproximaciones metodológicas para ampliar los modos de integrar el componente social ("S") en Sitios de Estudios SocioEcológicos a Largo Plazo (SESELP). Revista Chilena de Historia Natural, 83(1), 27-68.

Rozzi, R., Massardo, F., Medina, Y., Moses, K., Caballero, P., Camelio, E., Morales, V., Lewis, L., Goffinet, B., Méndez, M., Cavieres, L., Chávez, J., \& Russell, S. (2010b). Ecoturismo con lupa: integración de las ciencias ecológicas y la ética ambiental. Ambiente y Desarrollo, XXIV(2), 30-37.

Rozzi, R., Armesto, J., Gutiérrez, J., Massardo, F., Likens, G.... Kalin, M. T. (2012a). Integrating ecology and environmental ethics: Earth stewardship in the southern end of the Americas. BioScience, 62(3), 226-236.

Rozzi, R., Lewis, L., Massardo, F., Medina, Y., Moses, K... Goffinet, B. (2012b). Ecoturismo con lupa en el Parque Omora. Incluye el documental "El Viaje 
Invisible" por Jaime Sepúlveda, y fotografías de Adam Wilson. Punta Arenas, Chile: Ediciones Universidad de Magallanes.

Rozzi, R., Draguicevic, J. M., Arango, X., Sherriffs, M., Ippi, S.,... \& Massardo, F. (2014). Desde la ciencia hacia la conservación: el programa de educación y ética ambiental del Parque Etnobotánico Omora. En Rozzi, R., Jiménez J. E. (eds.), Ornitología Subantártica de Magallanes: Primera Década de Estudios de Aves en el Parque Etnobotánico Omora, Reserva de Biosfera Cabo de Hornos. Ediciones Universidad de Magallanes, Punta Arenas, Chile, pp. 299-308.

Tonucci, F. (2006). La ciudad de los niños. Un modo nuevo de pensar la ciudad. Buenos Aires. Argentina: Editorial

\section{Losada S. A.}

Vergara, C. (2006). Concepciones sobre la enseñanza y el aprendizaje en profesores de biología. Coherencia entre el discurso y la práctica de aula. Tesis doctoral para optar al grado de Doctor en Ciencias de la Educación. Pontificia Universidad Católica de Chile.

Vierikko, K., Elands, B., Niemelä, J., Andersson, E., Buijs, A., Fischer, L. K., ... \& Stahl, A. O. (2016). Considering the ways biocultural diversity helps enforce the urban green infrastructure in times of urban transformation. Current Opinion in Environmental Sustainability, 22, 7-12.

White, J. R. L. (2007). Raíces históricas de nuestra crisis ecológica. En Edición Especial "Ética Ambiental", Revista Ambiente y Desarrollo, 23, 78-86. 